\title{
We are the
}

Received: 2 January 2021

Supplementary materials: www.osf.io/9wdr5

Champions. The For correspondence: ivan.simko@usda.gov

\section{Index for}

\section{Evaluating}

Concentration of

Championships

Using a Sliding

\section{Window Approach}

Ivan Simko

USDA-ARS, Salinas, CA 93905, USA

ORCID: 0000-0002-8769-8477

Please cite as: Simko, I. (2021). We are the Champions. The Index for Evaluating Concentration of Championships Using a Sliding Window Approach. SportRXiv. https://doi.org/10.31236/osf.io/s8mhu

\section{ABSTRACT}

The concept of competitive balance is considered to be an essential aspect in the field of sport economics. This work describes a novel approach for measuring and evaluating competitive balance through concentration of championships. The concentration of championships was assessed using a sliding window approach with the length of five consecutive competitions (years) and a single 
competition (year) increment over the whole evaluated period. Because the sliding window was relatively short, the newly developed index, termed 'We Are the Champions' $\left(W A_{5}\right)$, is sensitive to rapid changes in competitive balance. The $W A C_{5}$ index, average $W A C_{5}$, expected $W A C_{5}$, and $\triangle W A C_{5}$ were applied to data from 68 competitions of several individual and team sports collected for the 1960-2020 period. The significance of indices was tested by resampling (bootstrapping and permutation). The results of the study show a growth in competitive balance of several ice hockey competitions (national and international), but decreasing competitive balance in Formula 1 racing and in several European soccer competitions. In soccer competitions, there was a substantially lower competitive balance in a league than in a domestic cup competition within each country/federation. The difference between the overall competitive balance in the most popular, North American, professional leagues and the top European soccer leagues is growing. A significant grouping of champions was determined for all sports involving individual athletes, but also for several team competitions.

Keywords: individual sport; team sport; grouping of champions; sliding windows; resampling; trends

\section{INTRODUCTION}

"We are the champions, my friends, and we'll keep on fighting 'til the end" sings Freddie Mercury from the British rock band Queen [1] in 'We are the Champions', a song that is popular among fans and athletes celebrating sport victories. Though only relatively few athletes can actually become champions, the prospect of winning a championship creates euphoria among athletes and fans alike. Participation in sport and demand for sport-related goods, live events, and broadcast have all risen steeply in North America since 1970s, Western Europe since 1980s, and in most of the other areas of the world since 1990s [2]. The estimated size of the global sports industry in 2018 was $\$ 1.3$ trillion [3]. Based on the global financial sport market, the number one sport is soccer (association football) with $43 \%$ market share, followed by American football (13\%), baseball (12\%), Formula 1 racing $(7 \%)$, basketball (6\%), ice hockey (4\%), tennis (4\%), and golf (3\%) [4]. The relatively unpredictable nature of sport with an uncertainty of outcome adds to the overall excitement for fans and may affect attendance of sport events [5]. Therefore, fans, managers, athletes, and also some economists occasionally express concern about the growing concentration of contenders to win championships [6,7]. To improve competitive balance among teams or individual athletes, several sport governing bodies made changes in a league or a tournament format and developed policies such as salary limitations, revenue sharing, draft rules, or roster limits $[8,6]$. However, the lack of competitive balance in major European soccer leagues where the majority of titles have been won by only a few teams, together with extraordinary popularity of these leagues indicates that fans may be less concerned with competitive balance than might be expected $[2,8,9]$.

Competitive balance can be measured as a within-season or between-seasons variation. The first evaluates dispersion of wins, points, or other parameters among teams in a specific season, while the second one analyses results across several seasons or tournaments. There are many methods to 
measure these variations, and no single method should be regarded as most appropriate [8]. The withinseason, competitive balance has been evaluated for a number of individual or team sports, including baseball, basketball, football, ice hockey, soccer, speed skating, table tennis, and tennis using the Herfindahl-Hirschman Index ( $\mathrm{HHI}$ ), Competitive Balance Ratio (CBR), the ratio of standard deviations (RSD), Gini coefficient and related Lorenz curve, relative entropy, and other, specific-sport-based criteria, such as points, scores, or time [10-22]. Between-seasons variation can be evaluated for an individual team using the team-specific variation in standing in different seasons (turnover) [11], or by measuring the concentration of championships in a given time period [8]. Because indices measuring the concentration of championships are based only on a relative frequency of championship success, they are unaffected by the distribution of wins, points, or scores accumulated during championships or by the championships format. This feature allows comparing indices of competitive balance across multiple sports and eras.

Previous studies analyzed concentration of championships across only a few competitions within a certain time period $[23,8,24]$, or for a single competition (occasionally more) in a few, nonoverlapping time periods $[25,23]$. Indices calculated from a whole evaluating period, however, do not allow for a detection of gradual changes in concentration of championships. The present study describes the use of a sliding window approach (together with novel indices) to detect gradual changes in concentration of championships. Because values in subsequent sliding windows are not independent from each other, statistical analyses of indices were performed using the model-free, block bootstrapping approach.

The concentrations of championships were evaluated in more than 60 major, professional leagues and tournaments, amateur (college level) tournaments, and some less economically influential leagues and competitions using a novel approach based on resampling. Though most studies in the literature analyze competitive balance in team sports, rather than in individual sports [13], this study includes for comparison also several tournaments for individual athletes. The objectives of the study were to use the newly developed indices and resampling approach to 1) compare differences in concentrations of championships across competitions, 2) evaluate trends in concentration of championships, and 3 ) determine a relative grouping of champions.

\section{METHOD}

\subsection{Data collection}

Data were collected for several popular sport leagues and major tournaments and also for some lesser known or amateur championships. These sports include association football ('soccer' henceforth), American football and Australian rules football (both 'football' henceforth), basketball, baseball, curling, ice hockey, and rugby union ('rugby' henceforth), and from individual sports tennis, golf, and Formula 1 racing ('F1' henceforth) (Table 1). Links to webpages with listed champions are provided in Supplementary materials. The effort has been made to keep only a single name for a team that modified its original name but was still considered to be an official successor of the original team. In women's 
individual sports, maiden names were matched to married names. When a league or a tournament was not held in some years, or a champion has not been declared, these years were omitted from data analysis. In four exceptions, two teams were declared to be official champions. In these situations, the calculations were performed using each champion separately and then averaging results. Though data were collected for all documented champions in evaluated competitions (some of them starting at the end of $19^{\text {th }}$ century), only the period from 1960 to 2020 was considered for the statistical analyses. This period approximately matches with the historical growth in popularity of sport [2] and also has more complete data for a larger number of leagues and tournaments than the older time period.

Table 1. List of 68 analyzed competitions.

\begin{tabular}{|c|c|c|c|c|c|c|}
\hline Competition $^{a}$ & Sport & Details & $\begin{array}{l}\text { Country or } \\
\text { region }\end{array}$ & Category & $\begin{array}{l}\text { Classificati } \\
\text { on }\end{array}$ & Years \\
\hline B-NBA & Basketball & & USA/Canada & Men & Team & $1947-2019$ \\
\hline B-NCAA & Basketball & College & USA & Men & Team & $1939-2019$ \\
\hline B-NCAA-W & Basketball & College & USA & Women & Team & $1982-2019$ \\
\hline B-Spa & Basketball & & Spain & Men & Team & $1958-2019$ \\
\hline Ba-Jap & Baseball & & Japan & Men & Team & $1950-2019$ \\
\hline Ba-Mex & Baseball & & Mexico & Men & Team & $1946-2020$ \\
\hline Ba-MLB & Baseball & & USA/Canada & Men & Team & $1903-2019$ \\
\hline$C-W C$ & Curling & & International & Men & Team & $1959-2019$ \\
\hline C-WC-W & Curling & & International & Women & Team & $1979-2019$ \\
\hline F-AFL & $\begin{array}{l}\text { Football- } \\
A U\end{array}$ & & Australia & Men & Team & $1897-2019$ \\
\hline F-NFL & $\begin{array}{l}\text { Football- } \\
\text { US }\end{array}$ & & USA & Men & Team & $1967-2020$ \\
\hline $\mathrm{F} 1$ & Formula 1 & & International & - & Individual & $1950-2019$ \\
\hline$F 1-E^{a}$ & Formula 1 & Engine & International & - & - & $1950-2019$ \\
\hline G-Mas & Golf & & International & Men & Individual & $1934-2019$ \\
\hline G-Open & Golf & & International & Men & Individual & $1870-2019$ \\
\hline G-PGA & Golf & & International & Men & Individual & $1916-2019$ \\
\hline G-US & Golf & & International & Men & Individual & $1895-2019$ \\
\hline $\mathrm{IH}-\mathrm{NHL}$ & Ice hockey & & USA/Canada & Men & Team & $1915-2019$ \\
\hline IH-Rus & Ice hockey & & Russia & Men & Team & $1947-2019$ \\
\hline IH-Svk & Ice hockey & & Slovakia & Men & Team & $1994-2019$ \\
\hline IH-Swe & Ice hockey & & Sweden & Men & Team & $1922-2019$ \\
\hline IH-WC & Ice hockey & & International & Men & Team & $1920-2019$ \\
\hline IH-WC-W & Ice hockey & & International & Women & Team & $1990-2019$ \\
\hline R-Eng & Rugby & & England & Men & Team & $1988-2019$ \\
\hline R-Fra & Rugby & & France & Men & Team & $1892-2019$ \\
\hline
\end{tabular}




\begin{tabular}{|c|c|c|c|c|c|c|}
\hline $\mathrm{R}-\mathrm{I} \& \mathrm{NI}$ & Rugby & & $\begin{array}{l}\text { Ireland/North } \\
\text { Ireland }\end{array}$ & Men & Team & $1991-2019$ \\
\hline R-Ken & Rugby & & Kenya & Men & Team & $1970-2019$ \\
\hline S-Bel & Soccer & League & Belgium & Men & Team & $1896-2019$ \\
\hline S-Bel-C & Soccer & Cup & Belgium & Men & Team & $1912-2019$ \\
\hline S-Bra & Soccer & & Brazil & Men & Team & $1959-2019$ \\
\hline $\mathrm{S}-\mathrm{CL}$ & Soccer & & International & Men & Team & $1956-2019$ \\
\hline $\mathrm{S}-\mathrm{CL}-\mathrm{C}^{\mathrm{a}}$ & Soccer & Countries & International & Men & - & $1956-2019$ \\
\hline S-CSR & Soccer & League & $\begin{array}{l}\text { Czechoslovaki } \\
\text { a }\end{array}$ & Men & Team & $1946-1993$ \\
\hline S-CSR & Soccer & Cup & $\begin{array}{l}\text { Czechoslovaki } \\
\text { a }\end{array}$ & Men & Team & $1961-1993$ \\
\hline S-CWC & Soccer & & International & Men & Team & $1961-1999$ \\
\hline S-CWC-C & Soccer & Countries & International & Men & Team & $1961-1999$ \\
\hline S-Cze & Soccer & League & Czechia & Men & Team & $1895-2019$ \\
\hline S-Cze-C & Soccer & Cup & Czechia & Men & Team & $1961-2019$ \\
\hline S-EL & Soccer & & International & Men & Team & $1972-2019$ \\
\hline S-EL-Ca & Soccer & Countries & International & Men & Team & $1972-2019$ \\
\hline S-Eng & Soccer & League & $\begin{array}{l}\text { England/Wale } \\
\mathrm{s}\end{array}$ & Men & Team & $1889-2019$ \\
\hline S-Eng-C & Soccer & Cup & England & Men & Team & $1972-2019$ \\
\hline S-Fra & Soccer & League & France & Men & Team & $1894-2019$ \\
\hline S-Fra-C & Soccer & Cup & France & Men & Team & $1918-2019$ \\
\hline S-Ger & Soccer & League & Germany & Men & Team & $1903-2019$ \\
\hline S-Ger-C & Soccer & Cup & Germany & Men & Team & $1935-2019$ \\
\hline S-Ita & Soccer & League & Italy & Men & Team & $1898-2019$ \\
\hline S-Ita-C & Soccer & Cup & Italy & Men & Team & $1922-2019$ \\
\hline S-MLS & Soccer & & USA/Canada & Men & Team & $1996-2019$ \\
\hline S-NCAA & Soccer & College & USA & Men & Team & $1959-2019$ \\
\hline S-Net & Soccer & League & $\begin{array}{l}\text { The } \\
\text { Netherlands }\end{array}$ & Men & Team & $1889-2019$ \\
\hline S-Net-C & Soccer & Cup & $\begin{array}{l}\text { The } \\
\text { Netherlands }\end{array}$ & Men & Team & $1899-2019$ \\
\hline S-Por & Soccer & League & Portugal & Men & Team & $1935-2019$ \\
\hline S-Por-C & Soccer & Cup & Portugal & Men & Team & $1922-2019$ \\
\hline S-Sco & Soccer & League & Scotland & Men & Team & $1891-2019$ \\
\hline S-Sco-C & Soccer & Cup & Scotland & Men & Team & $1874-2019$ \\
\hline S-Spa & Soccer & League & Spain & Men & Team & $1929-2019$ \\
\hline S-Spa-C & Soccer & Cup & Spain & Men & Team & $1903-2019$ \\
\hline
\end{tabular}




\begin{tabular}{lllllll} 
S-Svk & Soccer & League & Slovakia & Men & Team & $1925-2019$ \\
S-Svk-C & Soccer & Cup & Slovakia & Men & Team & $1961-2019$ \\
T-Aus & Tennis & & International & Men & Individual & $1905-2020$ \\
T-Aus-W & Tennis & & International & Women & Individual & $1922-2020$ \\
T-Eng & Tennis & & International & Men & Individual & $1877-2019$ \\
T-Eng-W & Tennis & & International & Women & Individual & $1884-2019$ \\
T-Fra & Tennis & & International & Men & Individual & $1891-2019$ \\
T-Fra-W & Tennis & & International & Women & Individual & $1897-2019$ \\
T-USA & Tennis & & International & Men & Individual & $1881-2019$ \\
T-USA-W & Tennis & & International & Women & Individual & $1887-2019$ \\
\hline
\end{tabular}

${ }^{a}$ Indicates four competitions that are not official but were added to the list to evaluate additional trends.

Links to original data and additional notes about competitions are provided in Supplementary materials.

\subsection{Measuring competitive balance}

This study uses a sliding window approach to evaluate distribution of champions in five consecutive years, with a single year increment. Such a relatively short period of time has been selected to better observe rapid changes in trends. In addition, when the number of competitions in the evaluated period is smaller than the number of teams or athletes participating in these individual competitions, no adjustment is needed to account for the number of participating teams when calculating the maximum competitive balance [1].

Several approaches can be used to evaluate concentration of championships from the fixed number of competitions that is not larger than the number of competing teams. To calculate the average concentration of championships at any given, five-year period, this study uses the average difference in the number of championships won by individual teams. (For simplicity, the term 'team' is used in descriptions, but the same approach applies to competitions of individual athletes. Similarly, terms 'years', 'championships', 'tournaments', and 'competitions' may be used interchangeably when describing the length of the evaluated period). Five consecutive championships (with a single champion in each of them) could be won by up to five teams. If one or more teams win multiple championships, the number of unique champions decreases. Therefore, the maximum competitive balance is reached when each championship is won by a different team. These different champions can be written as $A B C D E$ (or $A=1, B=1, C=1, D=1$, and $E=1$ ), and the average difference between wins of these five teams equals 0 . Opposite, the minimum competitive balance is reached when a single team wins all five championships; AAAAA ( $\operatorname{or} A=5, B=0, C=0, D=0$, and $E=0$ ). In this case, the average difference in the number of wins between 10 pairs of these five teams would be $20 / 10=2$. The average absolute differences for the other five, possible combinations of champions could be similarly calculated; 1.8 for $A A A A B, 1.6$ for $A A A B B, 1.4$ for $A A A B C, 1.2$ for $A A B B C$, and 0.8 for $A A B C D$. These values then can be scaled to the 0.0 (minimal competitive balance) to 1.0 (maximal competitive balance) range using formula: 'scaled value' = ('original value' -2$) /(-2)$. This scaled value has been termed 'WAC ${ }_{5}$ (We Are 
the Champions, 5-year) index. The $W C_{5}$ values for the seven possible combinations of champions are: $\mathrm{AAAAA}=0.0, \mathrm{AAAAB}=0.1, \mathrm{AAABB}=0.2, \mathrm{AAABC}=0.3, \mathrm{AABBC}=0.4, \mathrm{AABCD}=0.6$, and $\mathrm{ABCDE}=1.0$. The $W A C_{5}$ index thus takes into the consideration not only the number of unique champions during the fiveyear period, but also the distribution of wins among these champions (i.e., difference between $A A A B=$ 0.1 and $A A A B B=0.2$, and between $A A A B C=0.3$ and $A A B B C=0.4)$. Moreover, this index gives a larger weight to the last step leading to the maximum competitive balance (from $A A B C D=0.6$ to $A B C D E=1.0$ ) than to the first step from the minimum competitive balance (from $A A A A A=0.0$ to $A A A A B=0.1$ ). Such increased weight has been selected intentionally to accentuate the maximum competitive balance, however, different weights (or indices) could be used with the sliding window approach, if preferred.

\section{3. $\mathrm{WAC}_{5}$ comparison to other indices}

Besides $\mathrm{WAC}_{5}$, several other indices could be used to measure competitive balance through the concentration of championships. Because the maximum number of potential champions within a fiveyear period is exactly five $(n=5)$, the indices based on only these five potential champions are invariant to the total number of teams in the evaluated league (or to the change in the number of participating teams unless the number decreases below five). Notice an important difference among the maximum number of potential champions within a five-year period $(n=5)$, the number of teams that could potentially become champions (all teams participating in those championships), and the actual number of teams that won championships ( $N$ from 1 to 5 ). For example, a five-year record from a league with seven teams where four of the teams were champions $(N=4)$ can be written as $A=2, B=1, C=1, D=1, E=0$, $F=n . a$. , and $G=n . a$, where 'n.a.' means not applicable (not used in data analyses because no more than five teams could actually win championships).

When the concentration of championships is evaluated on the fixed number of years $(T=5)$ using the fixed number of potential champions $(n=5)$, several indices can be calculated from the actual number or the proportion of championships $\left(p_{i}\right)$ won by each of these five teams. It is important to emphasize, however, that these indices can only be used to estimate a between-season concentration of championships, but they do not indicate the strength of competitive balance within any of the evaluated seasons. To compare performances of indices with a dissimilar range and/or orientation, all indices had needed to be scaled to the 0.0 (for AAAAA) to 1.0 (for ABCDE) range [2] as 'scaled index value' = ('original index value' - 'original index value at AAAAA') / ('original index value at ABCDE' 'original index value at AAAAA').

\subsubsection{Number of champions}

Counting the number $(N)$ of teams that have won championships, regardless of the number of times each of the teams won, is a probably the simplest way of evaluating concentration of championships. The more teams were the champions, the higher was the competitive balance. The $N$ value ranges from 1 (for AAAAA) to 5 (for $A B C D E$ ). The scaled value of $N\left(N_{s}\right)$ is calculated as:

$$
N_{s}=(N-1) /(5-1)=(N-1) / 4
$$




\subsubsection{Variance}

When five different teams win one championship, each of them has the winning frequency of $p_{i}$ $=0.2$. If only a single team wins all championships, $p_{i}$ for this team is 1.0 , while for the four other teams that could potentially be winners during this period it is 0.0 . The variance $\left(\sigma^{2}\right)$ for the concentration of championships is calculated as:

$$
\sigma^{2}=\left(\Sigma\left(p_{i}-1 / T\right)^{2}\right) /(T-1)=\left(\sum\left(p_{i}-1 / 5\right)^{2}\right) /(5-1)=\left(\Sigma\left(p_{i}-0.2\right)^{2}\right) / 4
$$

The $\sigma^{2}$ values before scaling range from 0.2 (for AAAAA) to 0.0 (for ABCDE). The scaled value of $\sigma^{2}\left(\sigma_{s}^{2}\right)$ is calculated as:

$$
\sigma_{s}^{2}=\left(\sigma^{2}-0.2\right) /(0-0.2)=\left(\sigma^{2}-0.2\right) /(-0.2)
$$

\subsubsection{Standard deviation}

Standard deviation $(\sigma)$ is a square root of the variance $\left(\sigma^{2}\right)$, thus the values of an unscaled $\sigma$ range from 0.4472 (for AAAAA) to 0.0 (for ABCDE). The $\sigma$ index is calculated as:

$\sigma=\sqrt{ } \sigma^{2}$

The scaled value of $\sigma\left(\sigma_{s}\right)$ is calculated as:

$$
\sigma_{s}=(\sigma-0.4472) /(0-0.4472)=(\sigma-0.4472) /(-0.4472)
$$

\subsubsection{Simpson diversity index and its derivatives}

The Simpson diversity index [3] used in ecology is equivalent to the Herfindahl-Hirschman index (HHI) for market concentration [4] that was previously applied to evaluate concentration of championships in a given time period [1]. When used for both the fixed number of years and the fixed number of potential champions, the Simpson index is calculated as:

$$
D=\Sigma\left(p_{i}\right)^{2}
$$

The values for $D$ range from 1.0 (for AAAAA) to 0.2 (for $A B C D E$ ). The Simpson diversity index derivative that is also frequently used to evaluate diversity is the inverse (or reciprocal) Simpson index calculated as $1 / D$. Values for $1 / D$ at $T=n=5$ range from 1.0 (for AAAAA) to 5.0 (for ABCDE). Another derivative of the Simpson index used in diversity studies is $1-D$, however this index yields the same scaled values as $D$ and therefore it was not considered in the current evaluations.

The scaled value of $D\left(D_{s}\right)$ is calculated as:

$D_{s}=(D-1.0) /(0.2-1.0)=(D-1.0) /(-0.8)$

The scaled value of $1 / D\left(1 / D_{s}\right)$ is calculated as:

$$
1 / D_{s}=(1 / D-1.0) /(5.0-1.0)=(1 / D-1.0) / 4
$$

\subsubsection{Shannon index}

The Shannon index has been originally proposed to quantify entropy in text [5] but is likely the most preferred diversity index in ecology. When applied to evaluate concentration of championships, the index is calculated as:

$$
H^{\prime}=-\sum p_{i} \ln \left(p_{i}\right)
$$


The index ranges from 0.0 (for AAAAA) to $\ln (T)=1.6094$ (for $A B C D E$ ). The scaled values of Shannon index $\left(H^{\prime}{ }_{s}\right)$ are equivalent to the Pielou evenness $\left(J^{\prime}\right)$ index [6].

The scaled value of $H^{\prime}\left(H_{s}^{\prime}\right)$ is calculated as:

$H^{\prime}{ }_{s}=\left(H^{\prime}-0.0\right) /(1.6094-0.0)=H^{\prime} / 1.6094$

\subsubsection{Gini coefficient}

The Gini coefficient [7] that measures variability of distribution is frequently used in economic studies to compare inequality in wealth. When used to compare competitive balance on the fixed number of years and the fixed number of potential champions $(T=n=5)$, the coefficient is calculated as:

$G=\left(\Sigma\right.$ abs $\left.\left(p_{i}-p_{j}\right)\right) \times$ mean $p=\left(\sum\right.$ abs $\left.\left(p_{i}-p_{j}\right)\right) \times 0.2$

Where 'mean $p$ ' is the average proportion of wins. The unscaled coefficient ranges from 0.8 (for AAAAA) to 0.0 (for ABCDE).

The scaled value of $G\left(G_{s}\right)$ is calculated as:

$G_{s}=(G-0.8) /(0.0-0.8)=(G-0.8) /(-0.8)$

\subsubsection{Comparison of scaled indices}

When the number of years and the maximum number of potential champions were fixed $(T=n$ $=5)$, several indices yielded identical scaled values; the Simpson diversity index $\left(D_{s}\right)=$ the HerfindahlHirschman index $(\mathrm{HHI})=$ the index based on variance $\left(\sigma_{s}^{2}\right)$, the Shannon index $\left(H_{s}^{\prime}\right)=$ the Pielou evenness index $\left(J^{\prime}\right)$, and the We Are the Champions index $\left(\mathrm{WAC}_{5}\right)=$ the Gini coefficient $\left(G_{s}\right)$. In the case of identical results for two or more indices, only results from one of them are presented.

Scaled values of all tested indices increased in the order $A A A A A, A A A A B, A A A B B, A A A B C, A A B B C$, $A A B C D, A B C D E$, with the exception of the index based on counts $\left(N_{s}\right)$, which showed identical values for $A A A A B$ and $A A A B B(0.25)$, and for $A A A B C$ and $A A B B C(0.50)$ (Fig. 1). The largest increase in the index values between two successive combinations of champions (when ordered from the smallest to the largest competitive balance) were observed for the AAAAA to AAAAB step when using $D_{s}(0.40)$ and $H^{\prime}{ }_{s}$ (0.31), and for the AABCD to $A B C D E$ step when using $W^{\prime} A C_{5}(0.40), 1 / D_{s}(0.36)$, and $\sigma_{s}(0.32)$. Four pairwise differences had value of 0.25 when calculated using $N_{s}$ (Fig. 2a). These results imply that $D_{s}$ and $H_{s}^{\prime}$ may be preferred for analyses when the minimum competitive balance (AAAAA) needs to be accentuated, while $W A C_{5}, 1 / D_{s}$, and $\sigma_{s}$ may be more preferable for the analyses that emphasize the maximum concentration of championships ( $A B C D E)$. There was a substantial difference among indices in their sensitivity to the change in distribution of championship wins when the number of teams that won those championships $(N)$ was constant, i.e., differences between $A A A A B$ and $A A A B B$ (both $N=2$ ), and between $A A A B C$ and $A A B B C$ (both $N=3$ ) (Fig. 2b). The change was larger between $A A A A B$ and AAABB than between $\mathrm{AAABC}$ and $\mathrm{AABBC}$ when using $\sigma_{s}, D_{s}$, and $H_{s}^{\prime}$; smaller when applying $1 / D_{s}$, and equal when using $W_{A C}$. No effect was recorded, of course, for $N_{s}$ that considers only the number of different champions, not the distribution of wins. When compared to other tested indices, $W C_{5}$ gives the most weight to the final step in increase to maximum competitive balance ( $A A B C D$ to $A B C D E, 0.40$ ) while 
having an equal sensitivity (0.20) to the change in distribution of championship wins at $N=2$ and $N=3$.

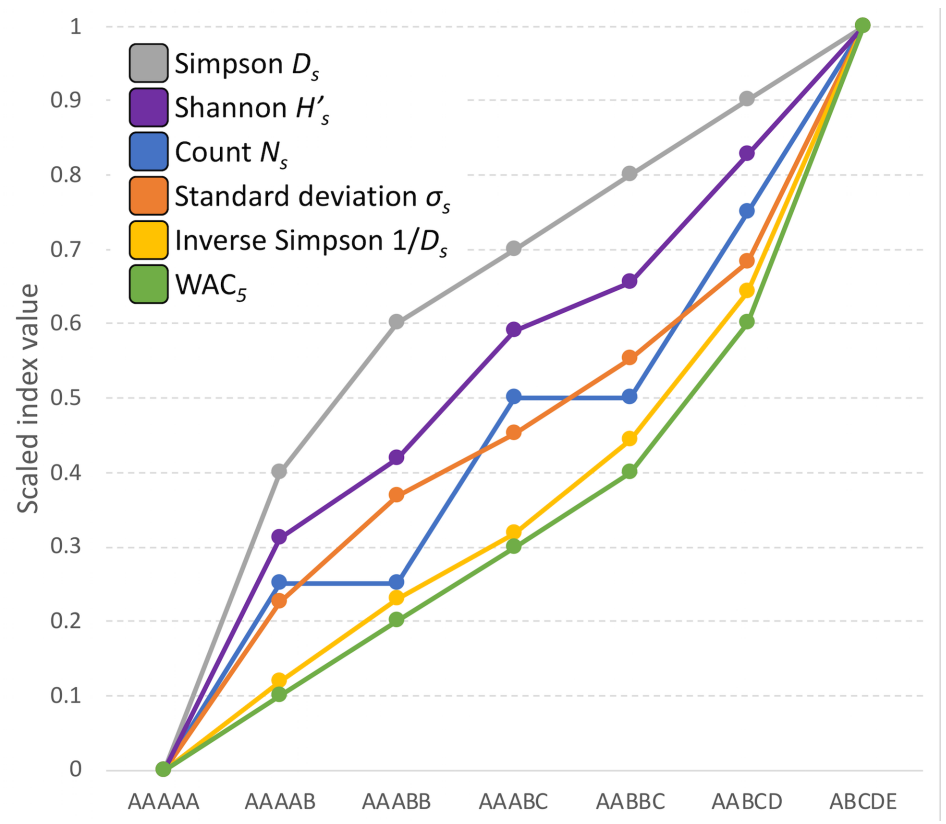

Figure 1. Absolute values of six scaled indices for seven possible combinations of champions. 

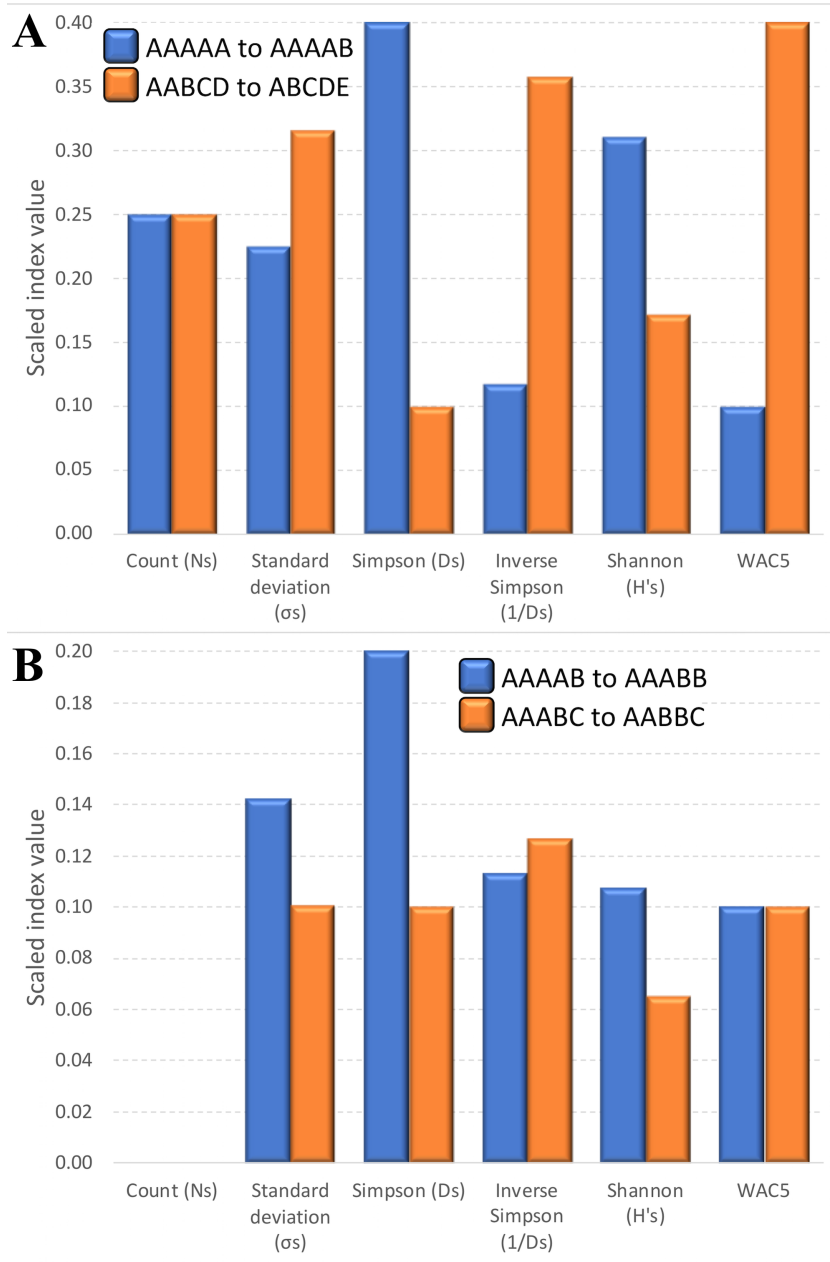

Figure 2. Absolute changes in the values of six scaled indices when the competitive balance increases from the minimal value (0.0) to the next step (AAAAA to $A A A A B)$ and when it increases from the penultimate step to the maximal value of 1.0 ( $A A B C D$ to $A B C D E$ ) (panel $A$, top). Absolute changes in the values of six scaled indices when the total number of champions remains the same, but the distribution of wins shifts (panel $B$, bottom). The AAAAB to $A A A B B$ step shows the change in values when the total number of champions is $N=2$, while the $A A A B C$ to $A A B B C$ step shows the change in values when the total number of champions is $N=3$.

\subsection{Data analysis}

\subsection{1. $W A C_{5}$ and $\mathrm{aWAC}_{5}$}

The $\mathrm{WAC}_{5}$ index indicates competitive balance (through concentration of championships) within a 5-year period. Individual $W_{A C}$ values calculated from subsequent sets of years (e.g, sliding window for years $1-5$, then for years 2-6) are not, however, fully independent from each other because champions 
in years 2-5 would be used in both calculations. To preserve the relationship between subsequent $\mathrm{WAC}_{5}$ values when estimating confidence intervals for 'average $\mathrm{WAC}_{5}$ ' ( $\left.\mathrm{aWAC}_{5}\right)$, the stationary block bootstrapping approach $[8,9]$ has been applied. This non-parametric, model-free approach divides data into blocks that are resampled with replacement and the new data series are then used to determine confidence intervals. The 'tsboot' and 'boot.ci' functions in R's 'boot' package $[10,11]$ were used to perform 100,000 resampling runs for each analyzed competition and to determine confidence intervals, respectively.

\subsection{2. $\mathrm{eWAC}_{5}$ and $\triangle W A C_{5}$}

Because each $\mathrm{WAC}_{5}$ is calculated from only five consecutive years (championships, tournaments), $\mathrm{aWAC}_{5}$ values cannot distinguish between the maximum competitive balance (aWAC $=$ 1.0) reached through repeated wins of the same five champions (e.g., $A B C D E-A B C D E$ over a 10-year evaluation period), or the one reached through wins of ten unique champions (ABCDE-FGHIJ). However, the actual number of champions and the frequency of their wins can be permutated over years and this new distribution of championship wins can be subsequently used to calculate $W \mathrm{CC}_{5}$ values. The average $\mathrm{WAC}_{5}$ values calculated from a large number of permutations are thus based on the random distribution of actual champions over the whole evaluation period and provide an effective statistical parameter that combines information about the number of champions and the frequency of their wins. This new index, termed 'expected $\mathrm{WAC}_{5}$ ' ( $\mathrm{eWAC}_{5}$ ), can distinguish between the combinations of champions described in the above example $(20,000$ permutations yielded eWAC 5 value of 0.604 for $A B C D E-A B C D E$, while $A B C D E-$ FGHIJ has always value of 1.0). The difference between eWAC $C_{5}$ and $a W A C_{5}$ values $\left(\triangle W A C_{5}=\mathrm{eWAC}_{5}-\right.$ $\mathrm{aWAC}_{5}$ ) in each competition indicates a relative grouping of the champions' wins in $\mathrm{aWAC}_{5}$ as compared to their random distribution over years $\left(\mathrm{eWAC}_{5}\right)$. Higher, positive values of the index are suggestive of a larger relative grouping of teams' wins. It needs to be emphasized, however, that the grouping of championship wins identified through this parameter for a five-year period is relative (based on the comparison with random distribution of wins), not absolute (e.g., actual count of wins by a champion in a sequence). This value is expected to be larger for sports involving individual athletes, as active careers of athletes are typically shorter than existence of sport teams, thus championship wins of individual athletes are more likely to be grouped together. Alternatively, this parameter could be calculated from logit transformed $\mathrm{eWAC}_{5}$ and $\mathrm{aWAC}_{5}$ values thus stretching both tails of their distributions. $\mathrm{eWAC}_{5}$ values for each evaluated competition were calculated from 10,000 permutations performed with Microsoft Excel for Mac v. 16.16.21 (Microsoft, Redmond, WA, USA).

\subsubsection{Change in competitive balance between eras}

To evaluate changes in competitive balance, the 1960 to 2020 period has been split into two eras, 1960 to 1989, and 1990 to 2020. Only competitions with at least 44 championships were considered for this analysis, therefore 13 out of 68 competitions were eliminated. Seven new datasets were added that combined $\mathrm{WAC}_{5}$ values from multiple competitions to compare the overall trends for 
certain sports, leagues, or geographic areas. These seven datasets were: N.Am-4 (combined results from four most economically important, professional leagues in North America: B-NBA, Ba-MLB, F-NFL, and $\mathrm{IH}-\mathrm{NHL}$ ), Euro-T5 (combined results from the top five European soccer leagues: S-Eng, S-Fra, S-Ger, S-Ita, and S-Spa), Euro-T5-C (combined cup competition results from the top five European soccer leagues: SEng-C, S-Fra-C, S-Ger-C, S-Ita-C, and S-Spa-C), Euro-Oth (combined results from all other European soccer leagues analyzed in this study), Euro-Oth-C (combined cup competition results from all other European soccer leagues analyzed in this study), T-Men (combined results of tennis Grand Slam tournaments for men: T-Aus, T-Eng, T-Fra, T-USA), and T-Women (combined results of tennis Grand Slam tournaments for women: T-Aus-W, T-Eng-W, T-Fra-W, T-USA-W). The significance of differences between $\mathrm{WAC}_{5}$ values for the two eras were determined using 100,000 bootstrapping. The monotonic trends in competitive balances were tested using the block bootstrapping version of the Mann-Kendall non-parametric test that is suitable for serially correlated (autocorrelated) data [12]. The 'bbsmk' function in R's 'modifiedmk' package $[13,11]$ was used to perform 50,000 resampling runs for each analyzed competition to determine the significance of Mann-Kendall $\tau$ statistics.

\section{RESULTS}

\subsection{Evaluation of competitive balance using $\mathrm{aWAC}_{5}$ values}

Competitive balance was analyzed on the set of 68 (mostly) annual competitions. The three oldest competitions included in analyses were G-Open (years 1870 - 2019), T-Eng (1877 - 2019), and TUSA (1881 - 2019) for individual sports, while for the team competitions they were S-Eng-C (1872 2019), S-Sco-C (1874 - 2019), and S-Eng (1889 - 2019) (Fig. 3 and 4, Table 1). For the period starting at 1960, the average $\mathrm{WAC}_{5}\left(\mathrm{aWAC}_{5}\right.$ ) ranged from 0.13 for IH-WC-W to 0.94 for S-CWC (Table 2). 


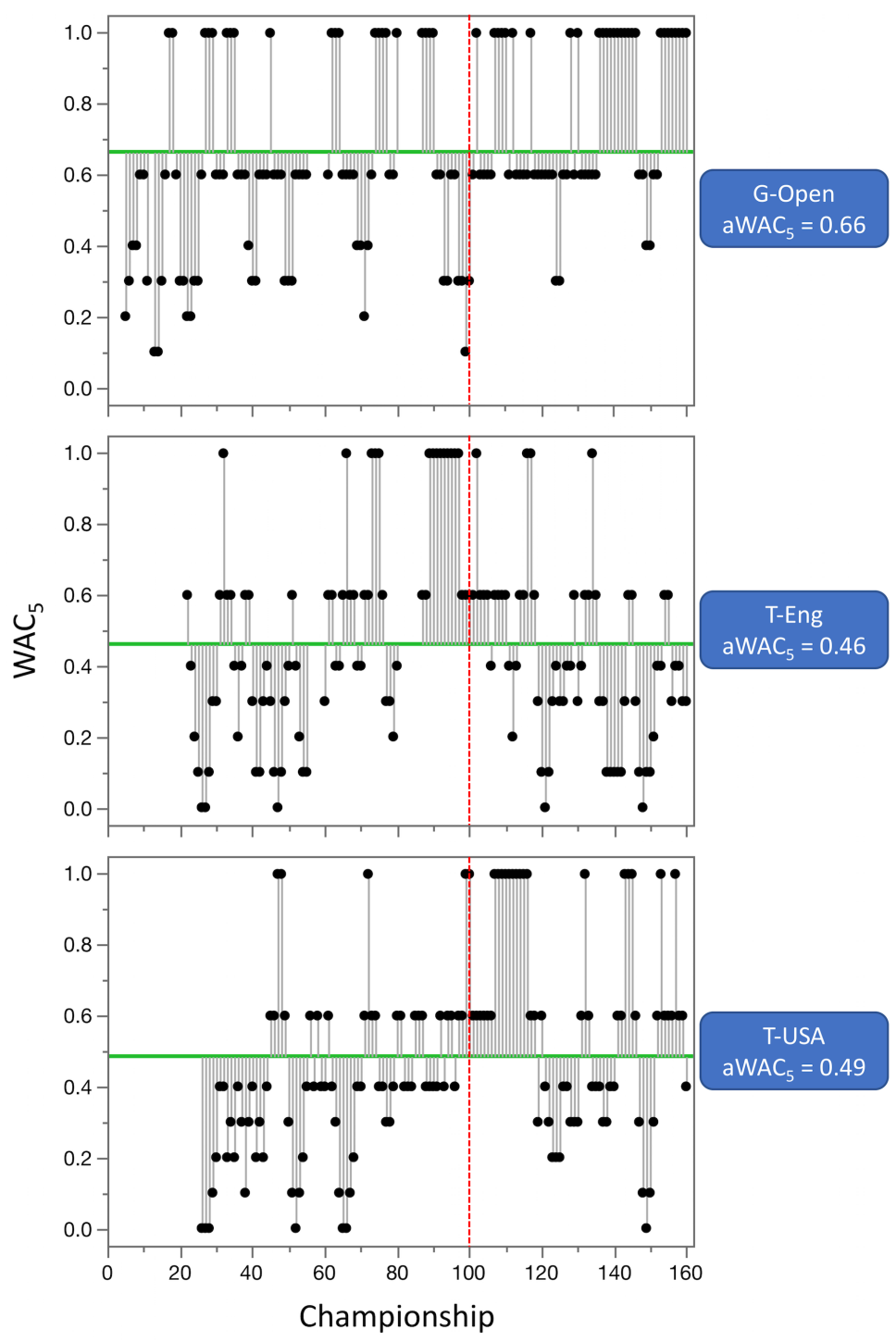

Figure 3. Historical outline of competitive balance for individual sports with the longest range of years. The oldest tournament (G-Open) started in 1860. Higher $W A_{5} / \mathrm{aWAC}_{5}$ values indicate a higher competitive balance. The black dots and the lines connected with them show $W C_{5}$ values for each championship (year) and their distance to $\mathrm{aWAC}_{5}$, respectively. $\mathrm{aWAC}_{5}$ for each competition is indicated by the green, horizontal line. The vertical red lines show year 1960, the beginning of the period that was used for detailed analysis of competitive balance. 


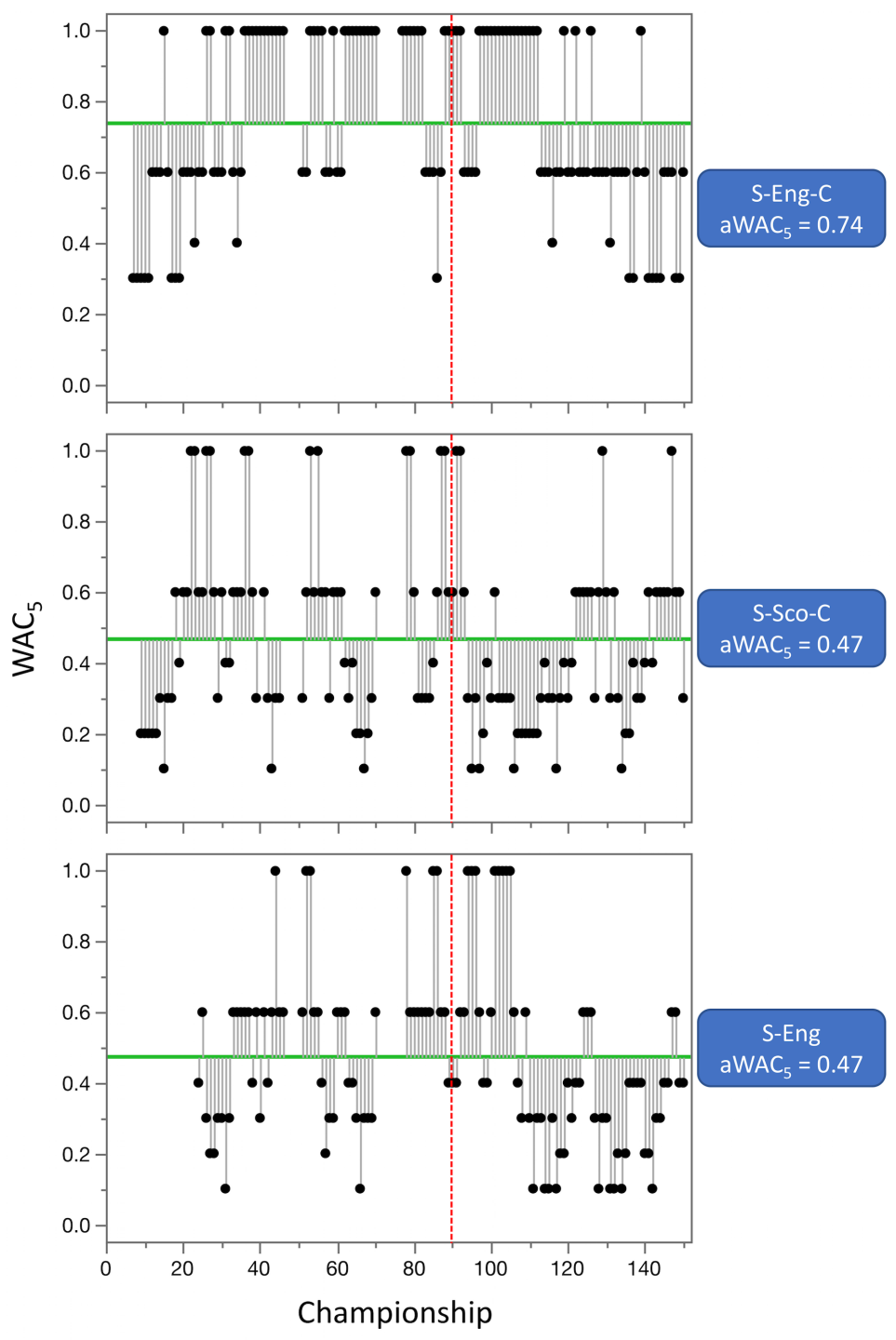

Figure 4. Historical outline of competitive balance for team sports with the longest range of years. The oldest competition (S-Eng-C) started in 1872. Higher $\mathrm{WAC}_{5} / \mathrm{aWAC}_{5}$ values indicate a higher competitive balance. The black dots and the lines connected with them show $\mathrm{WAC}_{5}$ values for each championship (year) and their distance to $\mathrm{aWAC}_{5}$, respectively. $\mathrm{aWAC}_{5}$ for each competition is indicated by the green, horizontal line. The vertical red lines show year 1960, the beginning of the period that was used for detailed analysis of competitive balance.

Table 2. Parameters of competitive balance calculated for 68 competitions.

\begin{tabular}{lllllll}
\hline Competition & eWAC $_{5}$ & \multicolumn{2}{c}{------} & $\mathrm{aWAC}_{5}$ & ----- & \multicolumn{2}{c}{$---\mathrm{WAC}_{5}---$} \\
& Mean & Mean & Cl95L & Cl95H & Value & Signif. \\
\hline B-NBA & 0.56 & 0.34 & 0.26 & 0.43 & 0.22 & $* * *$ \\
B-NCAA & 0.81 & 0.71 & 0.52 & 0.85 & 0.11 &
\end{tabular}




$\begin{array}{lllllll}\text { B-NCAA-W } & 0.63 & 0.47 & 0.38 & 0.57 & 0.16 & * * * \\ \text { B-Spa } & 0.27 & 0.23 & 0.13 & 0.34 & 0.04 & \\ \text { Ba-Jap } & 0.60 & 0.44 & 0.30 & 0.59 & 0.17 & * * \\ \text { Ba-Mex } & 0.59 & 0.56 & 0.48 & 0.64 & 0.03 & \\ \text { Ba-MLB } & 0.86 & 0.68 & 0.58 & 0.78 & 0.18 & * * * \\ \text { C-WC } & 0.29 & 0.28 & 0.22 & 0.36 & 0.02 & \\ \text { C-WC-W } & 0.44 & 0.39 & 0.30 & 0.49 & 0.05 & \\ \text { F-AFL } & 0.71 & 0.51 & 0.45 & 0.57 & 0.20 & * * * \\ \text { F-NFL } & 0.82 & 0.63 & 0.55 & 0.71 & 0.20 & * * * \\ \text { F1 } & 0.88 & 0.51 & 0.41 & 0.62 & 0.36 & * * * \\ \text { F1-E } & 0.59 & 0.23 & 0.18 & 0.29 & 0.36 & * * * \\ \text { G-Mas } & 0.92 & 0.75 & 0.66 & 0.84 & 0.16 & * * * \\ \text { G-Open } & 0.94 & 0.77 & 0.68 & 0.86 & 0.17 & * * * \\ \text { G-PGA } & 0.95 & 0.86 & 0.79 & 0.93 & 0.09 & * * * \\ \text { G-US } & 0.96 & 0.90 & 0.84 & 0.96 & 0.06 & * * \\ \text { IH-NHL } & 0.71 & 0.44 & 0.29 & 0.62 & 0.26 & * * * \\ \text { IH-Rus } & 0.43 & 0.27 & 0.14 & 0.41 & 0.17 & * * \\ \text { IH-Svk } & 0.49 & 0.35 & 0.30 & 0.40 & 0.14 & * * * \\ \text { IH-Swe } & 0.67 & 0.45 & 0.33 & 0.55 & 0.22 & * * * \\ \text { IH-WC } & 0.43 & 0.33 & 0.22 & 0.44 & 0.10 & * \\ \text { IH-WC-W } & 0.16 & 0.13 & 0.09 & 0.18 & 0.03 & \\ \text { R-Eng } & 0.52 & 0.33 & 0.25 & 0.42 & 0.19 & * * * \\ \text { R-Fra } & 0.71 & 0.50 & 0.38 & 0.63 & 0.21 & * * * \\ \text { R-I\&NI } & 0.58 & 0.47 & 0.36 & 0.58 & 0.12 & * \\ \text { R-Ken } & 0.49 & 0.23 & 0.18 & 0.28 & 0.26 & * * * \\ \text { S-Bel } & 0.41 & 0.34 & 0.29 & 0.39 & 0.06 & * * \\ \text { S-Bel-C } & 0.73 & 0.70 & 0.62 & 0.77 & 0.03 & \\ \text { S-Bra } & 0.75 & 0.56 & 0.45 & 0.68 & 0.19 & * * * \\ \text { S-CL } & 0.75 & 0.60 & 0.47 & 0.72 & 0.15 & * * \\ \text { S-CL-C } & 0.53 & 0.43 & 0.30 & 0.56 & 0.10 & \\ \text { S-CSR } & 0.55 & 0.31 & 0.23 & 0.41 & 0.23 & * * * \\ \text { S-CSR-C } & 0.58 & 0.62 & 0.53 & 0.73 & -0.05 & \\ \text { S-CWC } & 0.95 & 0.94 & 0.86 & 1.00 & 0.00 & \\ \text { S-CWC-C } & 0.64 & 0.68 & 0.58 & 0.80 & -0.04 & \\ \text { S-Cze } & 0.37 & 0.28 & 0.17 & 0.39 & 0.09 & \\ \text { S-Cze-C } & 0.59 & 0.54 & 0.43 & 0.66 & 0.04 & \\ \text { S-EL } & 0.90 & 0.76 & 0.65 & 0.85 & 0.14 & * * * \\ \text { S-EL-C } & 0.60 & 0.45 & 0.35 & 0.56 & 0.14 & * * \\ \text { S-Eng } & 0.62 & 0.43 & 0.31 & 0.58 & 0.19 & * *\end{array}$




\begin{tabular}{|c|c|c|c|c|c|c|}
\hline S-Eng-C & 0.73 & 0.70 & 0.58 & 0.83 & 0.03 & \\
\hline S-Fra & 0.69 & 0.42 & 0.33 & 0.52 & 0.26 & $* * *$ \\
\hline S-Fra-C & 0.78 & 0.66 & 0.60 & 0.73 & 0.12 & $* * *$ \\
\hline S-Ger & 0.49 & 0.45 & 0.34 & 0.57 & 0.04 & \\
\hline S-Ger-C & 0.67 & 0.63 & 0.52 & 0.74 & 0.04 & \\
\hline S-Ita & 0.44 & 0.41 & 0.30 & 0.51 & 0.03 & \\
\hline S-Ita-C & 0.70 & 0.64 & 0.53 & 0.75 & 0.06 & \\
\hline S-MLS & 0.76 & 0.63 & 0.56 & 0.70 & 0.13 & $* * *$ \\
\hline S-NCAA & 0.79 & 0.54 & 0.42 & 0.65 & 0.25 & $* * *$ \\
\hline S-Net & 0.35 & 0.30 & 0.25 & 0.37 & 0.05 & \\
\hline S-Net-C & 0.63 & 0.58 & 0.47 & 0.71 & 0.05 & \\
\hline S-Por & 0.26 & 0.21 & 0.16 & 0.25 & 0.06 & $* *$ \\
\hline S-Por-C & 0.52 & 0.50 & 0.42 & 0.57 & 0.02 & \\
\hline S-Sco & 0.26 & 0.19 & 0.13 & 0.26 & 0.07 & $* *$ \\
\hline S-Sco-C & 0.47 & 0.41 & 0.32 & 0.51 & 0.06 & \\
\hline S-Spa & 0.34 & 0.29 & 0.22 & 0.35 & 0.05 & $*$ \\
\hline S-Spa-C & 0.59 & 0.64 & 0.54 & 0.73 & -0.05 & \\
\hline S-Svk & 0.50 & 0.34 & 0.27 & 0.40 & 0.16 & $* * *$ \\
\hline S-Svk-C & 0.61 & 0.61 & 0.50 & 0.72 & -0.01 & \\
\hline T-Aus & 0.86 & 0.47 & 0.37 & 0.57 & 0.39 & $* * *$ \\
\hline T-Aus-W & 0.84 & 0.41 & 0.32 & 0.50 & 0.43 & $* * *$ \\
\hline T-Eng & 0.84 & 0.41 & 0.32 & 0.51 & 0.42 & $* * *$ \\
\hline T-Eng-W & 0.80 & 0.40 & 0.31 & 0.48 & 0.40 & $* * *$ \\
\hline T-Fra & 0.84 & 0.49 & 0.37 & 0.61 & 0.34 & $* * *$ \\
\hline T-Fra-W & 0.88 & 0.59 & 0.48 & 0.70 & 0.29 & $* * *$ \\
\hline T-USA & 0.90 & 0.59 & 0.46 & 0.72 & 0.31 & $* * *$ \\
\hline T-USA-W & 0.86 & 0.46 & 0.36 & 0.56 & 0.39 & $* * *$ \\
\hline
\end{tabular}

eWAC 5 : expected values of $W_{A C} ;$ aWAC $_{5}$ : observed average values of $W_{A C} ; \triangle W A C_{5}$ : difference between the expected and observed values of $W_{A C}\left(\triangle W A C_{5}=\mathrm{eWAC}_{5}-\mathrm{aWAC}_{5}\right)$. Higher values of aWAC and eWAC $C_{5}$ indicate a higher competitive balance. Higher positive values of $\triangle W A C_{5}$ indicate a higher relative grouping of champions.

$\mathrm{CI} 95 \mathrm{~L}$ and $\mathrm{Cl} 95 \mathrm{H}$ : the lower and upped bounds of the $95 \%$ confidence intervals. Asterisks indicate $\mathrm{p}$-values for $\triangle \mathrm{WAC}_{5}:{ }^{*} \mathrm{p}<0.1$ (suggestive), ${ }^{* *} \mathrm{p}<0.05$ (significant), $* * * \mathrm{p}<0.01$ (highly significant).

The exceptionally low competitive balance of IH-WC-W was caused by a very limited number of teams that won championships, with only two national teams winning all of them, Canada 14 and USA 11. Competitive balance was higher in the men's ice hockey championships reaching $\mathrm{aWAC}_{5}$ of 0.33 . Four ice hockey leagues had aWAC 5 values from 0.27 (IH-Rus), through 0.35 (IH-Svk), to 0.44 (IH-NHL) 
and 0.45 (IH-Swe). Low aWAC $_{5}$ at IH-Rus has been likely influenced by CSKA Moscow winning $45.0 \%$ of all championships (27 out of 60), with 25 out of them in the 30-year period (from 1960 to 1990). In basketball, the lowest $\mathrm{aWAC}_{5}$ values were detected for B-Spa (0.23) where majority of championships (50 out of $60,83.3 \%$ ) were won by either Real Madrid (33) or FC Barcelona (17). Competitive balance was higher at B-NBA (0.34), B-NCAA-W (0.47), and particularly at B-NCAA (0.71). In the latter two, college championships, the champions were determined in the play-off tournaments with only a singleelimination game between two matched-up teams. This kind of a knockout tournament may lead to more frequent elimination of favorites. The $\mathrm{WAC}_{5}$ values for baseball ranged from 0.44 (Ba-Jap), through 0.56 (Ba-Mex), to 0.68 (Ba-MLB). The lower $\mathrm{aWAC}_{5}$ for Ba-Jap is likely caused by 18 championship wins of Yomiuri Giants, nine of them between 1965 and 1973. Low levels of competitive balance were determined for curling when considering either men's (C-WC, 0.28) or women's (C-WC-W, 0.39) teams. World curling championships were dominated by Canada in both categories with $58.3 \%$ of championships won (35 out of 60 ) in the men's category, and $41.4 \%$ of championships won (17 out of 41 ) in the women's category. American football (F-NFL) and Australian rules football (F-AFL) leagues reached $\mathrm{aWAC}_{5}$ of 0.63 (F-NFL) and 0.51 (F-AFL), respectively. Reigning champions defended their titles in only $15.1 \%$ of championships in F-NFL (8 out of 53 ), and in $16.7 \%$ championships in F-AFL (10 out of 60). Rugby championships have had $\mathrm{aWAC}_{5}$ values in the range from 0.23 (R-Ken) to 0.50 (R-Fra). Low values at R-Ken were likely caused by frequent wins of reigning champions that happened in $53.1 \%$ of championships ( 26 out of 49).

Among soccer competitions, the highest aWAC 5 value (0.94) was detected for S-CWC (Table 2). A high $\mathrm{aWAC}_{5}$ value for this (already defunct) international competition was expected, because only teams winning their domestic cup competition could participate in it. In addition, when S-CWC champions qualified for a more prestigious S-CL competition, they have not been defending their title. Comparison among top three (former and current) European cups competitions showed $\mathrm{WWAC}_{5}$ increasing from 0.60 for S-CL, through 0.76 for S-EL, to 0.94 for S-CWC. When federations (or countries) of the champions were considered, the $W \mathrm{C}_{5}$ values were justifiably lower, because multiple champions could originate from the same federation. However, the $\mathrm{aWAC}_{5}$ values for federations (countries) increased in the same order as for individual teams, increasing from 0.43 for S-CL-C, through 0.45 for S-EL-C, to 0.68 for S-CWCC. The lowest aWAC 5 value among European leagues was detected at Scotland (S-Sco, 0.19), while the highest one was found at Germany (S-Ger, 0.45). The low competitive balance in S-Sco was due to a high frequency of championships won by only two teams, Celtic FC $(50.0 \%, 30$ out of 60$)$ and Rangers FC (38.3\%, 23 out of 60$)$. aWAC 5 values for non-European, soccer championships were higher than the highest one found at European leagues (S-Ger, 0.45) and reached 0.54 at S-NCAA (amateur, college competition with single-elimination tournament), 0.56 at S-Bra, and 0.63 at S-MLS (champions were determined in play-off elimination). When domestic cup competitions were compared across European federations (countries), the lowest competitive balance was detected again at S-Sco-C (0.41) and the highest one at S-Eng-C (0.70). The comparison of the two soccer competitions (league and cup) within

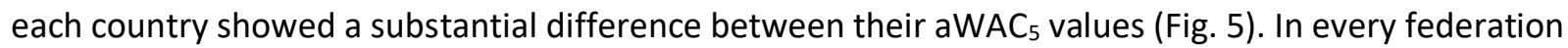
the values for leagues were lower with the difference ranging from 0.19 in Germany $(0.45 \mathrm{~S}$-Ger and 0.63 S-Ger-C, $p<0.1$ ) to 0.36 in Spain (0.29 S-Spa and 0.64 S-Spa-C, $p<0.01$ ). Because in every 
federation, teams from the top league compete, and can potentially win both domestic competitions (frequently called 'double'), the very large difference detected between $\mathrm{aWAC}_{5}$ values could seem unexpected. This difference may be caused by several factors, including the competition format and the team's preference or aspiration. While all analyzed leagues were played in a round-robin format (with occasional modifications), cup competitions were played as a knockout tournament with directelimination. Thus, loss led to immediate elimination (with exceptions when more than a single match was played) in cup competitions but not in leagues. Moreover, teams from lower tiers of domestic leagues see cup competitions as an opportunity to prove their worth against top teams (so called 'giant slayers'). Furthermore, top teams may have had a very busy schedule when also playing in a European cup competition, and therefore they could have rested a few or more of their best players.

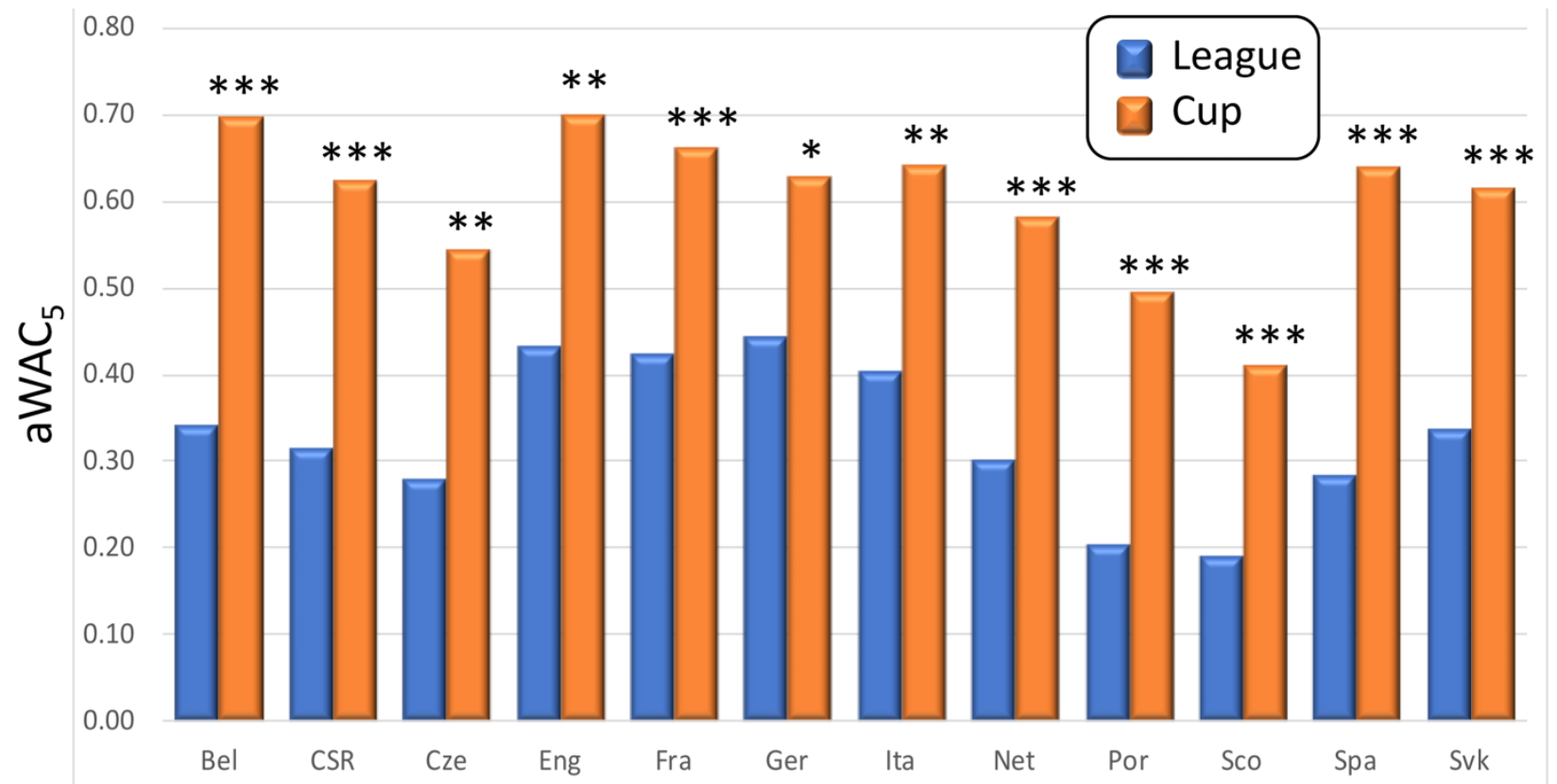

Figure 5. Comparison of competitive balance across 12 European soccer leagues and domestic cup competitions. Higher $\mathrm{aWAC}_{5}$ values indicate a higher competitive balance. Abbreviations for counties/federations are as follows: Bel - Belgium, CSR - (former) Czechoslovakia, Cze - Czechia, Eng England, Fra - France, Ger - Germany, Ita - Italy, Net - The Netherlands, Por - Portugal, Sco - Scotland, Spa - Spain, and Svk - Slovakia. Asterisks indicate the significance of difference between the pairs of competitions within each country/federation: ${ }^{*} p<0.1$ (suggestive), ${ }^{* *} p<0.05$ (significant), ${ }^{* * *} p<$ 0.01 (highly significant).

In competitions involving individual athletes, the $\mathrm{aWAC}_{5}$ values ranged from 0.40 (T-Eng-W) to 0.90 (G-US). All four golf tournaments have had very high $\mathrm{aWAC}_{5}$ values ranging from 0.75 for $\mathrm{G}$-Mas to 0.90 for G-US, placing them into top six of the 68 evaluated competitions (Table 2). In the $1960-2020$ period, the reigning champions were able to defend their titles only at the rate of $3.3 \%$ (2 out of 60 ) at G-US, 5.0\% (3 out of 60) at G-Mas and G-PGA, and 8.3\% ( 5 out of 60 ) at G-Open. For the four tennis, 
Grand Slam tournaments the aWAC 5 values in men's category ranged from 0.41 (T-Eng) to 0.59 (T-USA) and in women's category from 0.40 (T-Eng-W) to 0.59 (T-Fra-W). There was no obvious difference in the $\mathrm{aWAC}_{5}$ values between the two categories, and in both of them the lowest competitive balance was observed at Wimbledon (T-Eng-W, 0.40; T-Eng, 0.41), followed by Australian Open (T-Aus-W, 0.41; TAus, 0.47$)$. The $\mathrm{aWAC}_{5}$ value of 0.51 was detected for $\mathrm{F} 1$ individual drivers but only 0.23 for F1-E. This difference in values reflects that 60 championships were won by 29 drivers, but only 10 different engines were used in the winning race cars.

\subsection{Change in competitive balance from 1960 - 1989 to $1990-2020$}

The comparison of $\mathrm{aWAC}_{5}$ values calculated for two eras, the earlier one $(1960-1989)$ and the later one (1990 to 2020), was performed at 55 competitions that have had data for at least 44 championships or tournaments (Table 3 ) plus seven datasets that combine $\mathrm{WAC}_{5}$ from multiple competitions.

Table 3. Change in competitive balance from 1960 - 1989 to $1990-2020$ as determined by differences in $\mathrm{aWAC}_{5}$ values.

\begin{tabular}{|c|c|c|c|c|c|c|}
\hline \multirow[t]{2}{*}{ Competition } & \multicolumn{4}{|c|}{------------------- aWAC ${ }_{5}$----------------- } & \multicolumn{2}{|c|}{ Mann-Kendall } \\
\hline & $1960-1989$ & $1990-2020$ & Difference & Signif. of Diff. & $\tau$ & Signif. of $\tau$ \\
\hline B-NBA & 0.31 & 0.37 & 0.06 & & 0.08 & \\
\hline B-NCAA & 0.62 & 0.79 & 0.18 & & 0.17 & \\
\hline B-Spa & 0.10 & 0.35 & 0.25 & $* * *$ & 0.50 & $* * *$ \\
\hline Ba-Jap & 0.33 & 0.55 & 0.22 & & 0.26 & \\
\hline Ba-Mex & 0.59 & 0.53 & -0.06 & & -0.03 & \\
\hline Ba-MLB & 0.66 & 0.69 & 0.03 & & 0.15 & \\
\hline C-WC & 0.29 & 0.27 & -0.02 & & 0.11 & \\
\hline F-AFL & 0.49 & 0.53 & 0.04 & & -0.01 & \\
\hline F-NFL & 0.64 & 0.62 & -0.03 & & 0.08 & \\
\hline $\mathrm{F} 1$ & 0.65 & 0.38 & -0.27 & $* * *$ & -0.36 & $* * *$ \\
\hline F1-E & 0.26 & 0.20 & -0.07 & & -0.18 & \\
\hline G-Mas & 0.74 & 0.77 & 0.03 & & 0.14 & \\
\hline G-Open & 0.70 & 0.84 & 0.14 & & 0.17 & \\
\hline G-PGA & 0.92 & 0.80 & -0.12 & & -0.19 & $*$ \\
\hline G-US & 0.96 & 0.85 & -0.11 & $*$ & -0.12 & \\
\hline IH-NHL & 0.23 & 0.67 & 0.44 & $* * *$ & 0.49 & $* *$ \\
\hline IH-Rus & 0.10 & 0.43 & 0.33 & $* * *$ & 0.46 & $* *$ \\
\hline IH-Swe & 0.37 & 0.52 & 0.15 & & 0.40 & $* * *$ \\
\hline IH-WC & 0.20 & 0.45 & 0.25 & $* * *$ & 0.40 & $* * *$ \\
\hline R-Fra & 0.45 & 0.56 & 0.11 & & 0.09 & \\
\hline
\end{tabular}




\begin{tabular}{|c|c|c|c|c|c|c|}
\hline R-Ken & 0.15 & 0.28 & 0.13 & $* *$ & 0.33 & $* * *$ \\
\hline S-Bel & 0.33 & 0.35 & 0.02 & & 0.06 & \\
\hline S-Bel-C & 0.69 & 0.71 & 0.02 & & 0.05 & \\
\hline S-Bra & 0.51 & 0.60 & 0.09 & & 0.08 & \\
\hline $\mathrm{S}-\mathrm{CL}$ & 0.53 & 0.67 & 0.15 & & 0.17 & \\
\hline $\mathrm{S}-\mathrm{CL}-\mathrm{C}$ & 0.34 & 0.52 & 0.19 & & 0.13 & \\
\hline S-Cze-C & 0.44 & 0.63 & 0.19 & & 0.26 & $* *$ \\
\hline S-EL & 0.80 & 0.74 & -0.06 & & -0.22 & $* *$ \\
\hline S-EL-C & 0.58 & 0.39 & -0.19 & $*$ & -0.22 & \\
\hline S-Eng & 0.53 & 0.34 & -0.19 & $*$ & -0.25 & \\
\hline S-Eng-C & 0.85 & 0.55 & -0.29 & $* * *$ & -0.43 & $* * *$ \\
\hline S-Fra & 0.42 & 0.43 & 0.01 & & -0.04 & \\
\hline S-Fra-C & 0.68 & 0.64 & -0.04 & & -0.12 & \\
\hline S-Ger & 0.56 & 0.33 & -0.24 & $*$ & -0.43 & $* * *$ \\
\hline S-Ger-C & 0.66 & 0.60 & -0.06 & & -0.25 & $*$ \\
\hline S-Ita & 0.49 & 0.31 & -0.18 & $*$ & -0.27 & $* *$ \\
\hline S-Ita-C & 0.68 & 0.61 & -0.07 & & -0.26 & $* *$ \\
\hline S-NCAA & 0.44 & 0.62 & 0.18 & & 0.32 & $* *$ \\
\hline S-Net & 0.34 & 0.26 & -0.08 & & -0.19 & \\
\hline S-Net-C & 0.61 & 0.55 & -0.06 & & 0.01 & \\
\hline S-Por & 0.22 & 0.19 & -0.04 & & -0.10 & \\
\hline S-Por-C & 0.43 & 0.56 & 0.13 & & 0.02 & \\
\hline S-Sco & 0.26 & 0.12 & -0.15 & $*$ & -0.19 & \\
\hline S-Sco-C & 0.33 & 0.50 & 0.17 & $*$ & 0.24 & $*$ \\
\hline S-Spa & 0.27 & 0.30 & 0.02 & & 0.12 & \\
\hline S-Spa-C & 0.66 & 0.62 & -0.04 & & -0.01 & \\
\hline S-Svk-C & 0.54 & 0.67 & 0.13 & & 0.17 & \\
\hline T-Aus & 0.49 & 0.45 & -0.03 & & -0.16 & \\
\hline T-Aus-W & 0.38 & 0.45 & 0.07 & & 0.31 & $* *$ \\
\hline T-Eng & 0.48 & 0.34 & -0.14 & & -0.26 & $* *$ \\
\hline T-Eng-W & 0.40 & 0.40 & 0.00 & & -0.04 & \\
\hline T-Fra & 0.54 & 0.44 & -0.10 & & -0.32 & $* *$ \\
\hline T-Fra-W & 0.60 & 0.58 & -0.02 & & -0.10 & \\
\hline T-USA & 0.62 & 0.55 & -0.08 & & -0.15 & \\
\hline T-USA-W & 0.35 & 0.58 & 0.23 & $* * *$ & 0.22 & $*$ \\
\hline
\end{tabular}

Higher values of $\mathrm{aWAC}_{5}$ indicate a higher competitive balance. Positive difference shows a growing competitive balance in 1990 - 2020 as compared to the previous (1960 - 1989) period, while negative difference shows a decline in the competitive balance in the latter period. Similarly, positive values of 
Mann-Kendall $\tau$ show an overall increasing trend in competitive balance, while negative values indicate a decreasing trend. Asterisks indicate $p$-values for differences and $\tau$, respectively: ${ }^{*} p<0.1$ (suggestive), $* * \mathrm{p}<0.05$ (significant), *** $\mathrm{p}<0.01$ (highly significant).

At the individual competitions level, aWAC $\mathrm{WW}_{5}$ increased in 28 , stayed at the same level in one competition, and decreased in 26 . From the 28 competitions where $\mathrm{aWAC}_{5}$ increased, the difference was highly significant $(p<0.01)$ in five, significant $(p<0.05)$ in one, and suggestive $(p<0.1)$ in one of them. The largest increase in competitive balance, as indicated by the change in aWAC ${ }_{5}$ values, was observed for three ice hockey competitions; IH-NHL (increase of 0.44 from 0.23 to 0.67 ), IH-Rus (increase of 0.33 from 0.10 to 0.43 ), and IH-WC (increase of 0.25 from 0.20 to 0.45 ), followed by the basketball league in Spain (B-Spa, increase of 0.25 from 0.10 to 0.35 ) (Fig. 6). The largest increase in individual competitions was detected at women's US Open tennis tournament (T-USA-W), from 0.35 to 0.58 . From the 26 competitions where $\mathrm{aWAC}_{5}$ decreased from the earlier era, the difference was highly significant in two, and suggestive in five of them. The largest decrease in competitive balance was recorded for two soccer competitions and F1 racing; S-Eng-C (-0.29, from 0.85 to 0.55$)$, F1 (-0.27, from 0.65 to 0.38 ), and S-Ger (-0.24, from 0.56 to 0.33 ) (Fig. 7). Pooled data for tennis Grand Slam tournaments did not show and significant changes in $\mathrm{aWAC}_{5}$ values, though there was an indication that the overall competitive balance in men's competitions (T-Men) might have decreased (from 0.53 to 0.44 ) while increasing (from 0.43 to 0.51 ) in women's competitions (T-Women) (Table 3). 


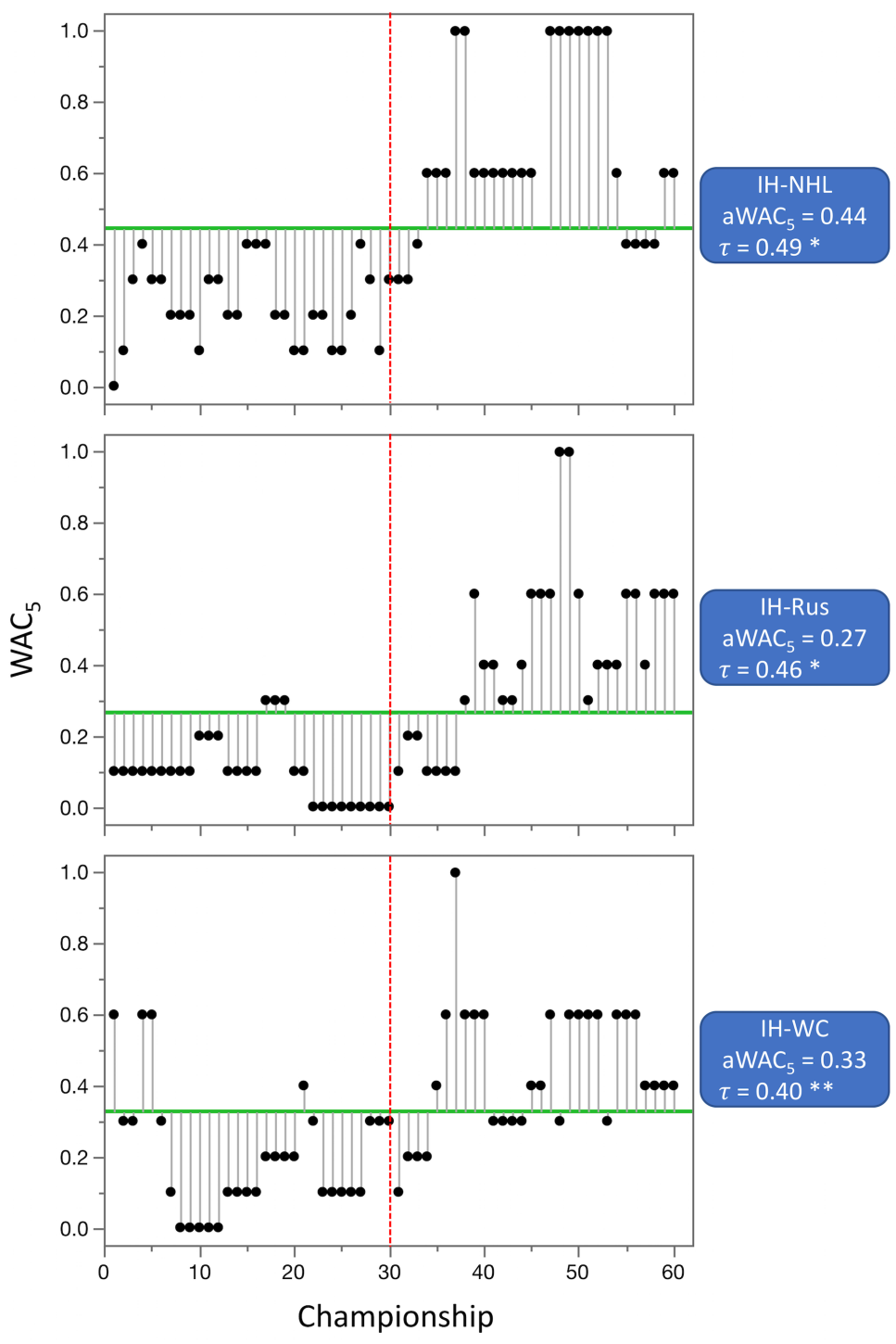

Figure 6. Competitions with the largest significant increase in competitive balance from 1960 - 1989 to 1990 - 2020. Higher $W_{A C} / a_{W A C}$ values indicate a higher competitive balance. The black dots and the lines connected with them show $W C_{5}$ values for each championship (year) and their distance to aWAC respectively. $\mathrm{aWAC}_{5}$ for each competition is indicated by the green, horizontal line. The championship number 1 correspondents to year 1960, while the championship number 61 correspondents to year 2020. The vertical red lines separate the two evaluated eras. Asterisks indicate the significance of MannKendall trend test $(\tau):{ }^{*} p<0.1$ (suggestive), $* * p<0.05$ (significant), $* * * p<0.01$ (highly significant). 


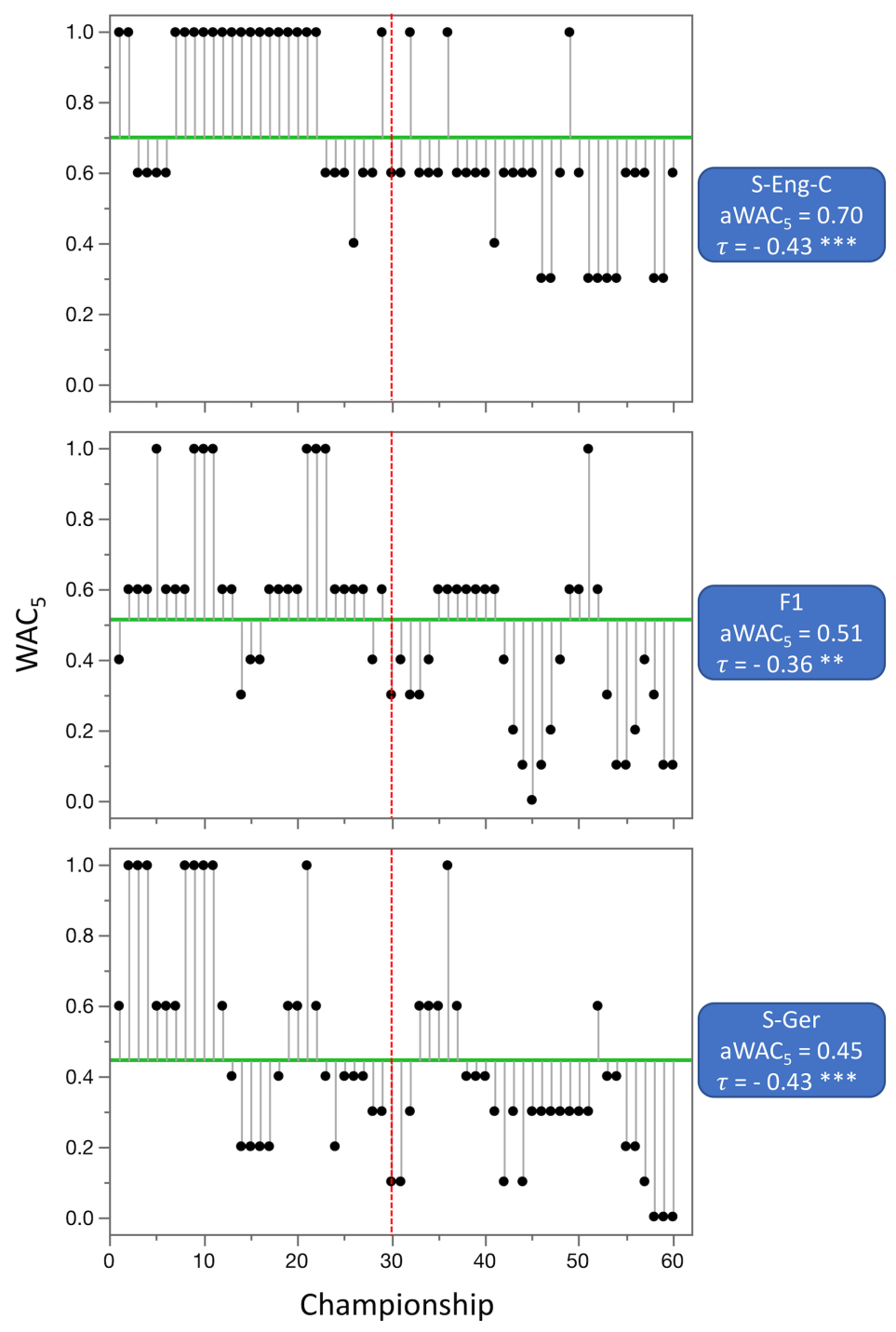

Figure 7. Competitions with the largest significant decrease in competitive balance from 1960 - 1989 to 1990 - 2020. Higher $W A_{5} / a_{W A C}$ values indicate a higher competitive balance. The black dots and the lines connected with them show $\mathrm{WAC}_{5}$ values for each championship (year) and their distance to $\mathrm{aWAC}_{5}$, respectively. $\mathrm{aWAC}_{5}$ for each competition is indicated by the green, horizontal line. The championship number 1 correspondents to year 1960, while the championship number 61 correspondents to year 2020. The vertical red lines separate the two evaluated eras. Asterisks indicate significance of the MannKendall trend test $(\tau):{ }^{*} p<0.1$ (suggestive), ${ }^{* *} p<0.05$ (significant), $* * * p<0.01$ (highly significant).

Competitive balance changed only negligibly in three out of the five professional, North American competitions, with a large economic impact; increased by 0.06 in B-NBA (from 0.31 to 0.37 ), by 0.03 in Ba-MLB (from 0.66 to 0.69 ), and decreased by 0.03 in F-NFL (from 0.64 to 0.62 ) (Fig. 8). The increase in competitive balance was highly significant in IH-NHL (by 0.44 , from 0.23 to 0.67 ). S-MLS has 
not been analyzed, because no data were available for the earlier era. When $W \mathrm{C}_{5}$ values from the four leagues with data for both eras were combined together (N.Am-4), they indicated a highly significant, overall increase in competitive balance (from 0.43 to 0.59 ) (Fig. 9).

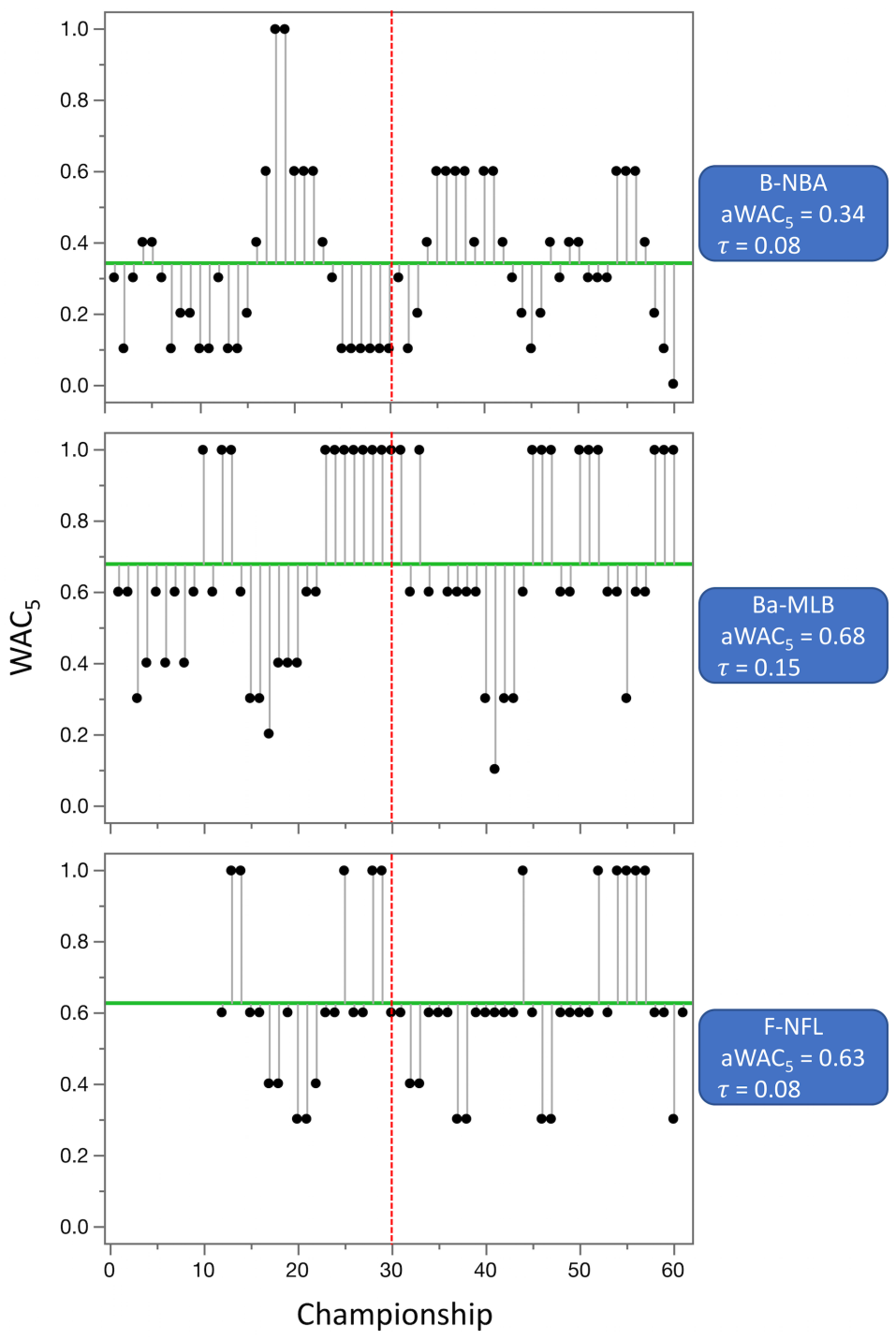

Figure 8. Three of the most popular North American, professional competitions with minimal change in competitive balance from 1960 - 1989 to 1990 - 2020. Higher $W A_{5} / a_{W A C}$ values indicate a higher competitive balance. The black dots and the lines connected with them show $W A_{5}$ values for each championship (year) and their distance to $\mathrm{aWAC}_{5}$, respectively. $\mathrm{aWAC}_{5}$ for each competition is indicated by the green, horizontal line. The championship number 1 correspondents to year 1960 , while the championship number 61 correspondents to year 2020. The vertical red lines separate the two evaluated eras. Asterisks indicate significance of the Mann-Kendall trend test $(\tau):{ }^{*} p<0.1$ (suggestive), $* * p<0.05$ (significant), *** $p<0.01$ (highly significant). Note that none of the tests was significant at $p$ $<0.1$. 


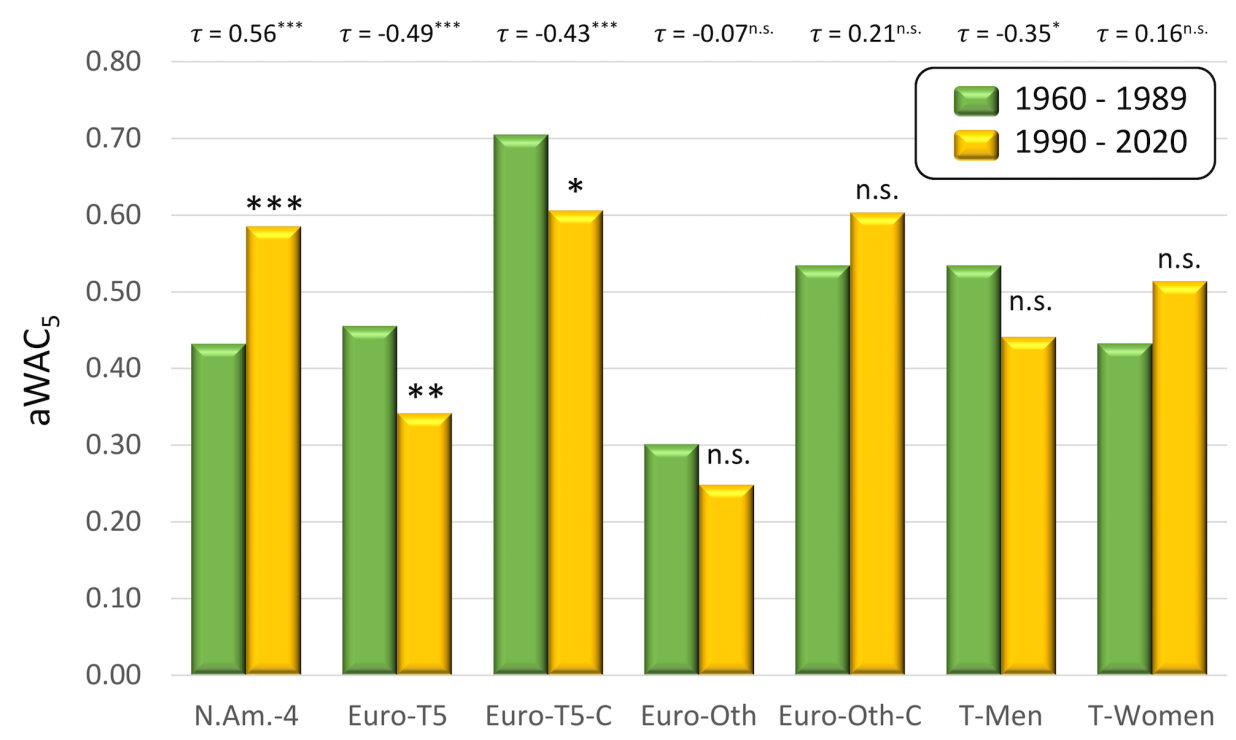

Figure 9. Change in competitive balance of seven datasets compiled from multiple competitions. N.Am-4 (four major, professional leagues in North America), Euro-T5 (top five European soccer leagues), EuroT5-C (domestic cup competitions from top five European soccer leagues), Euro-Oth (all other European soccer leagues analyzed in this study), Euro-Oth-C (domestic cup competition results from all other European soccer leagues analyzed in this study), T-Men (combined results of tennis Grand Slam tournaments for men), and T-Women (combined results of tennis Grand Slam tournaments for women). Higher $\mathrm{aWAC}_{5}$ values indicate a higher competitive balance. The $\tau$ values of the Mann-Kendall trend test are shown above the graph. Asterisks indicate the significance of difference between the pairs of competitions within each country/federation: ${ }^{*} p<0.1$ (suggestive), $* * p<0.05$ (significant), ${ }^{* * *} p<$ 0.01 (highly significant).

The situation was substantially different in the top five European soccer leagues, where the aWAC $_{5}$ values decreased substantially in S-Ger $(-0.24$, from 0.56 to $0.33, p<0.1)$, S-Eng $(-0.19$, from 0.53 to $0.34, \mathrm{p}<0.1)$, and S-Ita $(-0.18$, from 0.49 to $0.31, \mathrm{p}<0.1)$. A negligible increase in competitive balance was observed in S-Spa (0.02, from 0.27 to 0.30$)$ and S-Fra $(0.01$, from 0.42 to 0.43$)$. The combined values of aWAC 5 from these five federations (Euro-T5) showed a substantial decline in competitive balance (0.11 , from 0.46 to $0.34, p<0.05)$. Similarly, when cup competitions at these five federations were pooled together (Euro-T5-C), a decline in competitive balance was observed $(-0.10$, from 0.70 to $0.61, p$ $<0.1)$. In both combined datasets the decline appeared to be more pronounced in recent years. The lowest $\mathrm{aWAC}_{5}$ values for the league competitions during last 60 years was observed in 2019 (0.12) and for the cup competitions in 2018 (0.24) (Fig. 10). In comparison, average $\mathrm{aWAC}_{5}$ values from other analyzed countries or federations (Euro-Oth, Euro-Oth-C) did not deviate substantially from the overall mean calculated for the last 60 years. Though the overall, 60 -year mean in the top five federations was larger than in other, analyzed federations (Euro-T5 (0.40), Euro-Oth (0.27), Euro-T5-C (0.66), Euro-Oth-C (0.36)), the data from 2019 only showed a very different pattern (Euro-T5 (0.12), Euro-Oth (0.30), EuroT5-C (0.30), Euro-Oth-C (0.52)). It is not possible to determine, however, if this is a long-term trend or 
only a temporary anomaly. When the change in competitive balance was evaluated at the European cups level, non-significant increase was observed for S-CL (0.15, from 0.53 to 0.67$)$ and non-significant decrease of 0.06 for S-EL (from 0.80 to 0.74 ) (Fig. 11). A similar, but more pronounced pattern has been revealed then the competitive balance was calculated using origin (federation) of the champions. In such analysis, the competitive balance for S-CL-C increased by 0.19 (from 0.34 to 0.52 ), while decreased by 0.19 (from 0.58 to $0.39, p<0.1$ ) for E-EL-C. Nevertheless, the last three years of the Championship League (2017 to 2019) suggest a declining trend in competitive balance compared to the earlier years of this era (1990 to 2020) (Fig. 11).

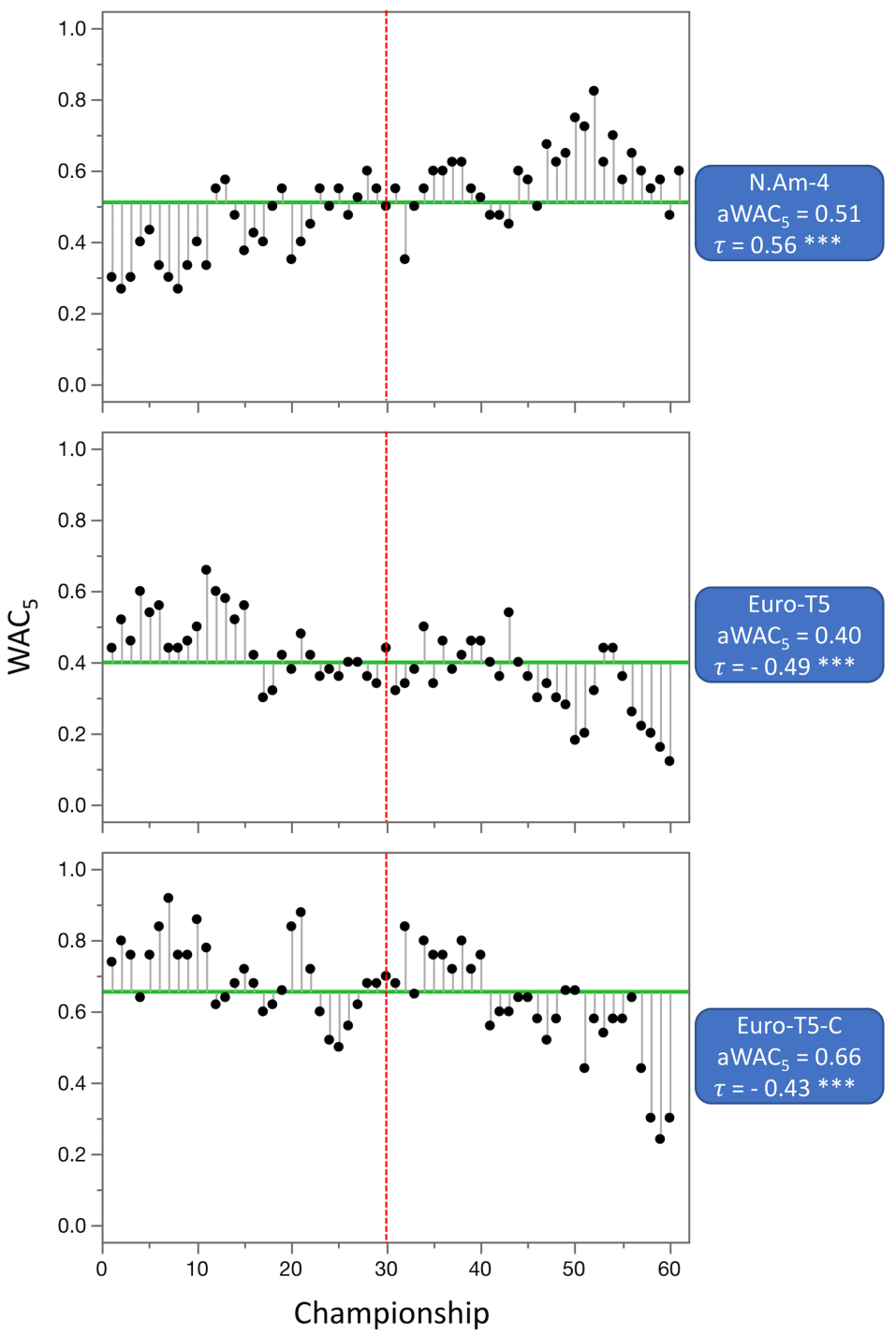

Figure 10. Three combined datasets with the largest change in competitive balance from $1960-1989$ to 1990 - 2020. N.Am-4 (four major, professional leagues in North America), Euro-T5 (top five European soccer leagues), and Euro-T5-C (domestic cup competitions from top five European soccer leagues). Higher $\mathrm{WAC}_{5} / \mathrm{aWAC}_{5}$ values indicate a higher competitive balance. The black dots and the lines 
connected with them show $\mathrm{WAC}_{5}$ values for each championship (year) and their distance to $\mathrm{aWAC}_{5}$, respectively. $\mathrm{aWAC}_{5}$ for each competition is indicated by the green, horizontal line. The championship number 1 correspondents to year 1960, while the championship number 61 correspondents to year 2020. The vertical red lines separate the two evaluated eras. Asterisks indicate significance of the MannKendall trend test $(\tau):{ }^{*} p<0.1$ (suggestive), ${ }^{* *} p<0.05$ (significant), $* * * p<0.01$ (highly significant).

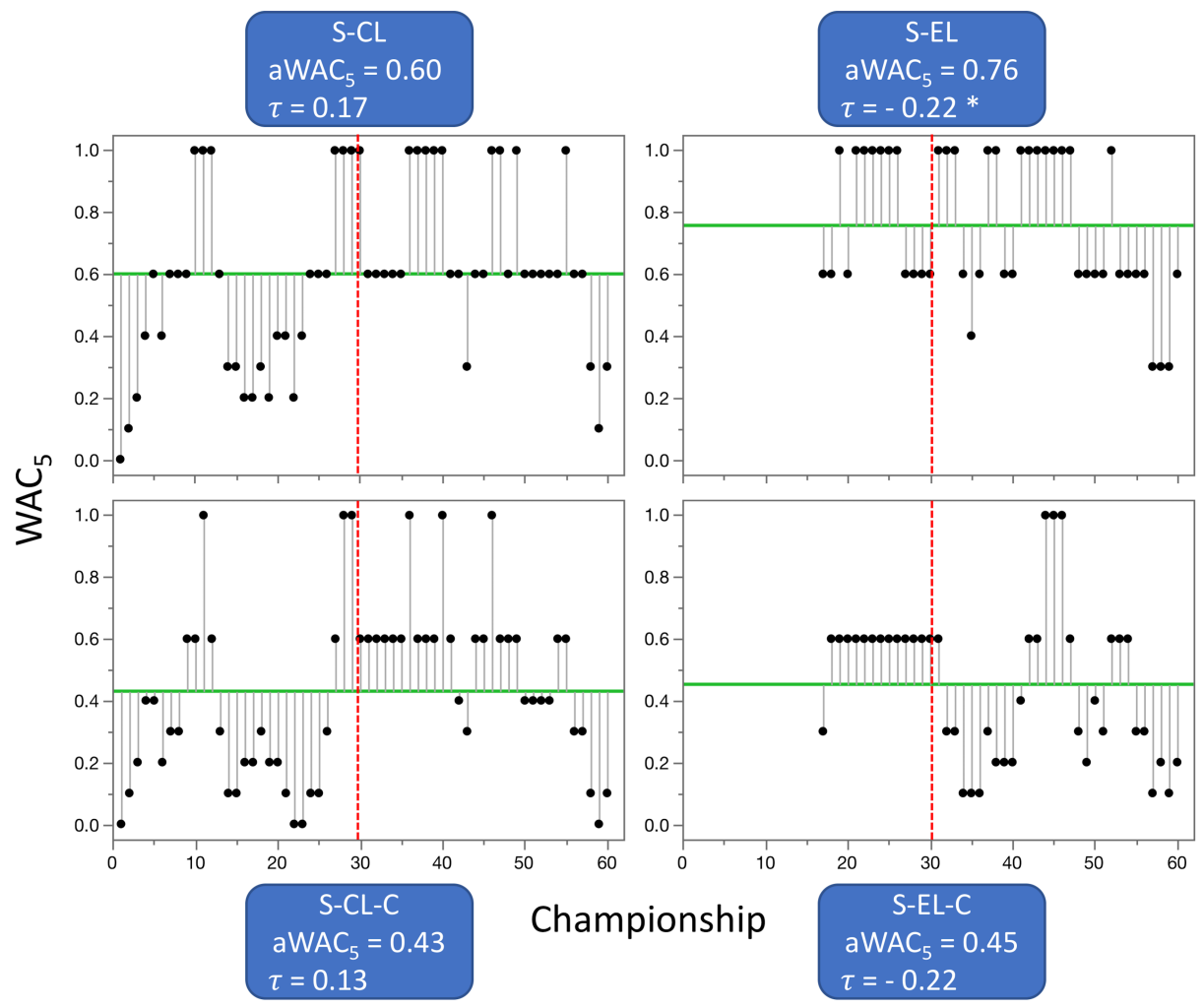

Figure 11. Changes in competitive balance of two European soccer's premier club competitions, the Championship League (S-CL) and the European League (S-EL). The top row shows competitive balance calculated at the individual club level, while the bottom row shows the results calculated at the country/federation level (when not the club, but country/federation of the champion was considered). Higher $\mathrm{WAC}_{5} / \mathrm{aWAC}_{5}$ values indicate a higher competitive balance. The black dots and the lines connected with them show $W_{A C}$ values for each championship (year) and their distance to aWAC , respectively. $\mathrm{aWAC}_{5}$ for each competition is indicated by the green, horizontal line. The championship number 1 correspondents to year 1960, while the championship number 61 correspondents to year 2020. The vertical red lines separate the two evaluated eras, $1960-1989$ from 1990 - 2020. Asterisks indicate significance of the Mann-Kendall trend test $(\tau):{ }^{*} p<0.1$ (suggestive), ${ }^{* *} p<0.05$ (significant), $* * * p<0.01$ (highly significant).

The values of Mann-Kendall $\tau$ ranged from $-0.43(p<0.01)$ for S-Ger to $0.50(p<0.01)$ for B-Spa (Table 3). A significant or suggestive decrease in competitive balance (negative values) was observed for 
10 competitions, while an increase (positive values) was recorded for 11 competitions. Out of 25 competitions that were determined to have significant or suggestive change in competitive balance by at least one of the two employed methods (difference in $\mathrm{WWAC}_{5}$ and $\tau$ ), four were identified only through differences in aWAC 5,10 were identified only when using the Mann-Kendall trend test, and 11 were detected by both methods.

\subsection{Expected concentration (eWAC 5 ) and relative grouping of champions $\left(\triangle W A C_{5}\right)$}

The expected eWAC 5 values were calculated from 10,000 permutations of the actual number and the frequency of champions reported for each of the 68 competitions. There was a positive, linear, significant correlation $(r=0.72, p<0.001)$, between $\mathrm{aWAC}_{5}$ and $\mathrm{WWAC}_{5}$ values. The eWAC $\mathrm{Walues}_{5}$ were in the range from 0.16 for IH-WC-W to 0.96 for G-US (Table. 2), indicating a very low and a very high balance in these two competitions. Similarly, as for $\mathrm{aWAC}_{5}$, very high eWAC 5 values were determined for all golf competitions $(0.92-0.96)$ and S-CWC (0.95). Contrasting, a very low balance of competition was found for several soccer leagues (S-Por, S-Sco, S-Spa, S-Net, S-Cze, and S-Bel, from 0.26 to 0.41), basketball league in Spain (B-Spa, 0.27), and men's world curling championships (C-WC, 0.29).

The difference $\left(\triangle W A C_{5}\right)$ between the observed $\left(a W A C_{5}\right)$ and the expected $\left(e W C_{5}\right) W C_{5}$ values $\left(\triangle W A C_{5}=e W A C_{5}-a W A C_{5}\right)$ can be used as an indicator of a relative grouping of champions within average 5 -year period. $\triangle W A C_{5}$ was highly significant $(p<0.01)$ in 32 competitions, significant $(p<0.05)$ in nine, suggestive $(p<0.1)$ in three, and non-significant $(p>0.1)$ in 24 of them (Table. 2$)$. The largest $\triangle W A C_{5}$ was observed for T-Aus-W (0.43), followed by several other tennis tournaments (between 0.42 and 0.29 ) and F1 racing (0.36). These results were expected because individual athletes have shorter active carriers than teams, thus their championship wins have to be grouped. A very high $\triangle W A C_{5}$ was found also for F1-E (0.36) because different groups of engines were used at different times in history of racing. The absolute values of $\triangle W A C_{5}$ were smaller for golf ( 0.06 to 0.17 ) because both $\mathrm{WWAC}_{5}$ and $\mathrm{aWAC}_{5}$ were close to the upper tail of the scale, but all of those differences were still either significant

(G-US), or highly significant (G-PGA, G-Mas, and G-Open). Among collective sports the largest $\triangle \mathrm{WAC}_{5}$ of 0.26 was observed for S-Fra, IH-NHL, and R-Ken, followed by 0.25 for S-NCAA. In all of these competitions, the high groupings were likely caused by several 'dynasties' winning majority of championships at different time. For example, in France soccer league (S-Fra) AS Saint-Etienne won seven championships in ten years (1967 - 1976), then Marseille (Olympique de Marseille) won four championships in a row (1989 - 1992), followed by Lyon (Olympique Lyonnais) winning seven champions in a row between 2002 and 2008, and more recently, Paris Saint-Germain F.C. won six championships in seven years $(2013-2019)$. The competitions with the lowest $\triangle W A C_{5}$, indicating no relative grouping of champions as compared to their random distribution was observed for S-Svk-C (0.01), S-CWC-C (-0.04), S-Spa-C (-0.05), and S-CSR-C (-0.05).

\section{DISCUSSION}

The exact comparison of results obtained with the indices proposed in this study with previously 
published findings is not possible because evaluations were performed for different time periods, competitions, and/or using a within-season variance. However, a limited comparison with published studies shows a generally good agreement with the current findings. Analysis of Lorenz curves revealed a smaller competitive balance in B-NBA than in IH-NHL [14]. Both of these leagues exhibited the higher concentration of championships than F-NFL. Both, the $\mathrm{aWAC}_{5}$ and $\mathrm{eWAC}_{5}$ values for these three competitions have grown in the same order as previously reported; B-NBA (0.34 and 0.56), IH-NHL (0.44 and 0.71 ), and F-NFL (0.63 and 0.82) (Table 2). The $\mathrm{HHI}$ index has been used to evaluate concentrations of champions over a ten-year period $(2006-2016)$ in eight leagues. Overall, the competitive balance was substantially higher in four North American professional competitions than in top four European soccer leagues [1]. The competitive balance in these competitions decreased in the order: F-NFL, B-NBA, Ba-MLB, IH-NHL, S-Eng, S-Ger, S-Ita (equal to S-Ger), and S-Spa. The current study also revealed a difference between these eight leagues, with the $\mathrm{aWAC}_{5}$ values ranging from 0.37 (B-NBA) to 0.69 (Ba$\mathrm{MLB}$ ) for the leagues in North America, and from 0.30 (S-Spa) to 0.34 (S-Eng) for the four European soccer leagues, when only the period of 1990 to 2020 was considered (as these years overlap with those in the previous study). eWAC 5 values, that were calculated only for the whole evaluated period of 1960 -2020, indicated a similar pattern for six out of eight leagues (Table 2). However, the competitive balance in English premiership ( $\mathrm{S}-\mathrm{Eng}$, eWAC $\mathrm{C}_{5}=0.62$ ) was estimated to be higher than in $\mathrm{B}-\mathrm{NBA}\left(\mathrm{eWAC} \mathrm{C}_{5}\right.$ $=0.56)$. Results from the present study also agree with the previous findings that $B a-M L B\left(e W A C_{5}=\right.$ 0.86) can be considered as the most balanced of the eight leagues and that among the four European soccer leagues S-Eng (eWAC $5=0.62$ ) is the most balanced [15]. However, while previously S-Ita was found to be the most imbalanced league using 1969 - 2004 data [15], current study shows that the most imbalanced of the four leagues is S-Spa (eWAC ${ }_{5}=0.34$ ), where 46 out of 60 championships $(76.7 \%)$ were won by only two teams, Real Madrid CF (27 out of $60,45.0 \%$ ) and FC Barcelona (19 out of $60,31.7 \%$ ). From the soccer leagues analyses in this study the highest imbalance in concentration of championships was found in S-Sco $\left(a W A C_{5}=0.19\right)$ and S-Por $\left(a W A C_{5}=0.21\right)$. These results match with the preceding report [16].

Several studies evaluated changes in competitive balance over time, usually in North American leagues and in top European soccer leagues. Feddersen, Maennig [15] examined a within season balance in Ba-MLB, F-NFL, IH-NHL, B-NBA, S-Ita, S-Ger, S-Eng, S-Spa using HHI and several other parameters. For the entire observation period (1969-2004), 12 trends indicated growing imbalance, 19 trends indicated growing balance, and 17 trends were insignificantly different from zero. Jang et al. [17] determined that the balance over time (52 to 116 evaluated seasons) improved in Ba-MLB, B-NBA, F-NFL, and IH-NHL but decreased in S-Eng, S-Ger, S-Ita, and S-Spa. Based on the aWAC 5 and $\tau$ values, the competitive balance significantly increased in IH-NHL, not changed significantly in B-NBA Ba-MLB, F-NFL, and S-Spa, and decreased at the suggestive or significant level in S-Eng (aWAC 5 only), S-Ita, and S-Ger (Table 3). Considering that these results were detected using a different time period and evaluation parameters, the grouping of leagues is rather similar. Moreover, comparison of data pooled from the top European soccer leagues (Euro-T5) and four of the professional leagues in North America (N.Am-4) shows a growing difference in competitive balance between the two. While the $\mathrm{aWAC}_{5}$ values were similar in the 1960 - 1989 period (0.46 for Euro-T5, 0.43 for N-Am.-4), they highly significantly increased in N.Am-4 to 
0.59 but significantly decreased in Euro-T5 to 0.34 (Table 3). Identical trends were observed using the Mann-Kendall test ( $\tau$ of -0.49 and 0.56 for Euro-T5 and N-Am.-4, respectively). Similarly, the decrease of competitive balance has also been observed on pooled data for cup competitions from these five soccer federations (Euro-T5-C, decrease from 0.70 to $0.61, \tau=-0.43$ ) (Fig. 9). When a within season competitive balance was evaluated by Groot [18], the author reported increased superiority of champions (1977 2002) in England (S-Eng) and The Netherlands (S-Net), and to the lesser extend also in Italy (S-Ita) and France (S-Fra). Probably the most studied from all soccer leagues was the English Premier League. Szymanski [19] evaluated the number of teams accounting for top positions in 1977 - 1998 and reported relatively stable competitive balance. Other authors, however, described decline in competitive balance when analyzing the period of 1888 - 2007 [20], 1947 - 2004 [21], 1948 - 2008 [22], $1963-2005$ [23] and $1992-2010$ [24]. Most of the authors noted that the significant decline in competitive balance started between 1987 to mid-1990s. These data match well with the observations presented in this study, where $\mathrm{aWAC}_{5}$ values decreased from 0.53 in the $1960-1989$ period, to 0.34 in the $1990-2020$ period. The $\tau$ value of -0.25 indicated a similar, though nonsignificant trend. Though it was not an objective of the current study to identify factors leading to these changes in competitive balance, previous authors suggested that the change may be related to the back-pass rule [25], the Bosman ruling [20], and/or the increased inequalities in resources between clubs [26].

Several indices were previously developed for the evaluation of between-seasons competitive balance [27], including those measuring concentration of championships [28]. The sliding windows approach, described in this study, combined with the stationary block bootstrapping adds to the flexibility of analyses of competitive balance. Depending on specific requirements of the study, the sliding window approach can be used to analyze various indices and lengths of evaluating periods. The minimal length of the sliding window to calculate WAC index is two $\left(W A C_{2}\right)$, when only two subsequent championships are considered. When the minimal length window is used, the values of $W \mathrm{CC}_{2}$ index can only be 0 , when a reigning champion defends the title, or 1 , when any other team/individual athlete wins the championship. Therefore, this special case of the WAC index can be termed 'Defending Champion Index' $(\mathrm{DCl})$ to emphasize that its values depend only on the success of the reigning champion. The average $\mathrm{DCl}(\mathrm{aDCl}=\mathrm{aWAC})$ value for the whole evaluated period is equal to the proportion $(\mathrm{P})$ of championships that were not won by reigning champions. Though the $\mathrm{P}$ and $\mathrm{aDCl}$ values are always identical, their confidence intervals are not. For example, if 10 out of 100 championships were won by defending champions, $\mathrm{P}=\mathrm{aDCl}=0.9$. The $95 \%$ confidence interval for $\mathrm{P}$ goes from 0.83 to 0.95 (range of 0.12 ) without continuity correction and from 0.82 to 0.95 (range of 0.13 ) with continuity correction. However, these confidence intervals do not take into consideration the relationship between subsequent $\mathrm{DCl}$ values; therefore, they are identical regardless of the spacing between defended championships. In difference, the stationary block bootstrapping approach (with the block geometric mean of 5 and 100,000 bootstrapping) yielded values from 0.75 to 1.00 (range of 0.25 ) when those ten defended championships were won in a row, but the confidence interval was only from 0.86 to 0.94 (range of 0.08 ) when those defended championships were spaced evenly (every $10^{\text {th }}$ championship was defended). Thus, the stationary block bootstrapping approach should be used to calculate aDCl confidence intervals even though $\mathrm{aDCl}=\mathrm{P}$. Besides $\mathrm{aDCl}, \mathrm{eDCl}$ and $\triangle \mathrm{DCl}$ can be calculated 
for the Defending Champion Index as was previously described for the $\mathrm{WAC}_{5}$ index.

\section{CONCLUSIONS}

There are fewer measures of between-seasons competitive balance available than for withinseason competitive balance. The between seasons competitive balance based on a sliding window approach and the number of champions within a five-year period described in this work thus provides valuable information for sports governing bodies when evaluating the effect of policies (e.g., salary limitations, revenue sharing, draft rules, or roster limits) or other introduced changes (a league or a tournament format, number of teams, etc.). The current study describes indices developed only from the potential or real number of champions thus making them invariant to the total number of teams (if $\geq$ 5 ) in the evaluated league (adding weak teams to the league does not increase a between-season competitive balance) or the league/tournament format. The index $\left(\mathrm{WAC}_{5}\right)$ combined with the sliding window approach, however, is flexible enough to indicate gradual changes in the concentration of championships. The indices described in this study are:

- $\quad$ eWAC $_{5}$ that indicates the average, expected concentration on champions at any given 5-year period. The index is based on calculating concentration of championships in a 5-year period from random distribution of actual champions over the whole evaluation period.

- $\quad \mathrm{aWAC}_{5}$ that indicates the average, observed concentration of championships at any given 5-year period. The index confidence intervals are determined through block bootstrapping of actual champions and their order over the whole evaluation period. Because this index is based on a short sliding window, it has a good sensitivity to rapid changes in competitive balance.

- $\quad \triangle W A C_{5}\left(\triangle W A C_{5}=e W A C_{5}-a_{W A C}\right)$ that indicates a relative grouping of champions at any given 5 -year period as compared to their random distribution determined through permutation.

- $\quad D C l$ that shows the proportion of championships that were not won be reigning champions. The application of these indices to data collected for 68 competitions and seven datasets with pooled results from multiple competitions revealed:

- A highly competitive balance at all golf tournaments.

- A low competitive balance at several European soccer leagues and ice hockey competitions.

- A substantially larger competitive balance in the domestic soccer cup competition as compared to the league in the same country (federation)

- An increasing competitive balance in several ice hockey competitions.

- A decreasing competitive balance in several European soccer leagues, and domestic cup competitions.

- A growing difference in competitive balance between the most popular North American professional leagues and the top European soccer leagues.

- A major grouping of champions in sports involving individual athletes, but also some team sport competitions. 


\section{Funding information}

The author received no financial support for the research, authorship, and/or publication of this article.

\section{Data and Supplementary Material Accessibility}

Links to original data and additional notes about competitions are provided in Supplementary materials at www.osf.io/9wdr5.

\section{REFERENCES}

1. Queen (1977): We Are the Champions. In: News of the World. EMI Records.

2. Andreff, W., Szymanski, S. (2006): Handbook on the Economics of Sport. Edward Elgar Publishing, Cheltenham, UK.

3. Plunkett Research (2020): Sports Industry Statistic and Market Size Overview, Business and Industry Statistics. https://www.plunkettresearch.com/statistics/Industry-Statistics-Sports-Industry-Statisticand-Market-Size-Overview/. Accessed February 212020.

4. SportyCo (2017): How Big is the Sports Industry? https://medium.com/sportyfi/how-big-is-the-sportsindustry-630fba219331. Accessed February 212020.

5. Forrest, D., Simmons, R. (2002): Outcome Uncertainty and Attendance Demand in Sport: The Case of English Soccer. Journal of the Royal Statistical Society: Series D (The Statistician) 51(2), 229-241.

6. Sanderson, A.R., Siegfried, J.J. (2003): Thinking About Competitive Balance. Journal of Sports Economics 4(4), 255-279.

7. Penn, R., Berridge, D. (2019): Competitive Balance in the English Premier League. European Journal for Sport and Society 16(1), 64-82.

8. Leeds, M.A., Von Allmen, P., Matheson, V.A. (2018): The Economics of Sports. Routledge, New York.

9. Szymanski, S. (2003): The Economic Design of Sporting Contests. Journal of Economic Literature 41(4), 1137-1187.

10. Depken, C.A. (1999): Free-agency and the Competitiveness of Major League Baseball. Review of Industrial Organization 14(3), 205-217.

11. Humphreys, B.R. (2002): Alternative Measures of Competitive Balance in Sports Leagues. Journal of Sports Economics 3(2), 133-148.

12. Jang, H., Lee, Y.H., Fort, R. (2019): Winning in Professional Team Sports: Historical Moments. Economic Inquiry 57(1), 103-120.

13. Koning, R.H. (2009): Sport and Measurement of Competition. De Economist 157(2), 229-249.

14. Owen, P.D., King, N. (2015): Competitive Balance Measures in Sports Leagues: The Effects of Variation in Season Length. Economic Inquiry 53(1), 731-744.

15. Owen, P.D., Ryan, M., Weatherston, C.R. (2007): Measuring Competitive Balance in Professional Team Sports Using the Herfindahl-Hirschman Index. Review of Industrial Organization 31(4), 289-

DOI: $10.31236 /$ osf.io/s8mhu 
302.

16. Fort, R., Quirk, J. (1995): Cross-subsidization, Incentives, and Outcomes in Professional Team Sports Leagues. Journal of Economic Literature 33(3), 1265-1299.

17. Horowitz, I. (1997): The Increasing Competitive Balance in Major League Baseball. Review of Industrial Organization 12(3), 373-387.

18. Koning, R.H. (2000): Balance in Competition in Dutch Soccer. Journal of the Royal Statistical Society: Series D (The Statistician) 49(3), 419-431.

19. Zheng, J., Oh, T., Kim, S., Dickson, G., De Bosscher, V. (2018): Competitive Balance Trends in Elite Table Tennis: the Olympic Games and World Championships 1988-2016. Journal of Sports Sciences 36(23), 2675-2683.

20. Lopez, M.J., Matthews, G.J., Baumer, B.S. (2018): How often does the best team win? A unified approach to understanding randomness in North American sport. The Annals of Applied Statistics 12(4), 2483-2516.

21. Scully, G.W. (1989): The Business of Major League Baseball. University of Chicago Press, Chicago, IL.

22. Noll, R.G. (1991): Professional Basketball: Economic and Business Perspectives. In: Mangan, J.A., Staudohar, P.D. (eds.) The Business of Professional Sports. University of Illinois Press, Urbana, IL.

23. Gerrard, B. (2004): Still Up for Grabs? Maintaining the Sporting and Financial Viability of European Club Soccer. In: Fort, R.D., Fizel, J. (eds.) International Sports Economics Comparisons. Praeger Publishers, Westport, CT.

24. Quirk, J., Fort, R.D. (1997): Pay Dirt: The Business of Professional Team Sports. Princeton University Press, Princeton.

25. Eckard, E.W. (1998): The NCAA Cartel and Competitive Balance in College Football. Review of Industrial Organization 13(3), 347-369.

26. Peet, R.K. (1975): Relative diversity indices. Ecology 56(2), 496-498.

27. Simpson, E.H. (1949): Measurement of diversity. Nature 163(4148), 688-688.

28. Rhoades, S.A. (1993): The Herfindahl-Hirschman index. Fed. Res. Bull. 79, 188.

29. Shannon, C.E. (1948): A mathematical theory of communication. Bell System Technical Journal 27(3), 379-423.

30. Pielou, E.C. (1966): The measurement of diversity in different types of biological collections. Journal of Theoretical Biology 13, 131-144.

31. Ceriani, L., Verme, P. (2012): The origins of the Gini index: extracts from Variabilità e Mutabilità (1912) by Corrado Gini. The Journal of Economic Inequality 10(3), 421-443.

32. Kunsch, H.R. (1989): The Jackknife and the Bootstrap for general stationary observations. The Annals of Statistics, 1217-1241.

33. Politis, D.N., Romano, J.P. (1994): The Stationary Bootstrap. Journal of the American Statistical Association 89(428), 1303-1313.

34. Canty, A., Ripley, B. (2020): Package 'boot'. Version 1.3-25.

35. R Core Team (2019): R: A language and environment for statistical computing. R Foundation for Statistical Computing, Vienna, Austria. https://www.R-project.org/.

36. Önöz, B., Bayazit, M. (2012): Block bootstrap for Mann-Kendall trend test of serially dependent data. 
Hydrological Processes 26(23), 3552-3560.

37. Patakamuri, S.K., O'Brien, N. (2020): Package 'modifiedmk'. Version 1.5.0.

38. Feddersen, A., Maennig, W. (2005): Trends in Competitive Balance: Is There Evidence for Growing Imbalance in Professional Sport Leagues? Hamburg Contemporary Economic Discussion Paper(01).

39. Groot, L.F. (2005): European Football: Back to the 1950s. Available at SSRN:

https://ssrn.com/abstract=726727 or http://dx.doi.org/10.2139/ssrn.726727.

40. Szymanski, S. (2001): Income Inequality, Competitive Balance and the Attractiveness of Team Sports: Some Evidence and a Natural Experiment from English Soccer. The Economic Journal 111(469), F69F84.

41. Lee, Y.H., Fort, R. (2012): Competitive Balance: Time Series Lessons from the English Premier League. Scottish Journal of Political Economy 59(3), 266-282.

42. Michie, J., Oughton, C. (2004): Competitive Balance in Football: Trends and Effects. The Sports Nexus, London, UK.

43. Curran, J., Jennings, I., Sedgwick, J. (2009): 'Competitive Balance' in the Top Level of English Football, 1948-2008: An Absent Principle and a Forgotten Ideal. The International Journal of the History of Sport 26(11), 1735-1747.

44. Goossens, K. (2006): Competitive Balance in European Football: Comparison by Adapting Measures: National Measures of Seasonal Imbalance and Top 30. Rivista di Diritto ed Economia Dello Sport 2, 77-122.

45. Ramchandani, G. (2012): Competitiveness of the English Premier League (1992-2010) and Ten European Football Leagues (2010). International Journal of Performance Analysis in Sport 12(2), 346360.

46. Kent, R.A., Caudill, S.B., Mixon Jr, F.G. (2013): Rules Changes and Competitive Balance in European Professional Soccer: Evidence from an Event Study Approach. Applied Economics Letters 20(11), 1109-1112.

47. Manasis, V., Ntzoufras, I. (2014): Between-seasons Competitive Balance in European Football: Review of Existing and Development of Specially Designed Indices. Journal of Quantitative Analysis in Sports 10(2), 139-152.

DOI: $10.31236 /$ osf.io/s8mhu 